$$
\begin{aligned}
& \text { (2) } \\
& \text { كلية التريبية } \\
& \text { جامعة سوهاج } \\
& \text { مجلة شباب الباحثين } \\
& \text { دور الموسسات التعليمية اللانظامية في تمقيق العدالة الاجتماعية }
\end{aligned}
$$

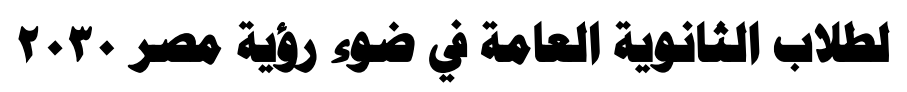

$$
\begin{aligned}
& \text { (بجثمشتقمن مسالةعلمية شخصص أصول التبية ) } \\
& \text { |عداد } \\
& \text { مدرس أصول التربية مدمد أحمد مدية } \\
& \text { بكلية التربية بقنا - جامعة جنوب الوادي } \\
& \text { أ.دا صبري الأنصاري إبر اهيم أصول التربية المتفرغ } \\
& \text { والعميد الأسبق } \\
& \text { كلية التربية - جامعة جنوب الوادي الأبي } \\
& \text { أ/ أنور عبد الرحيم أحمد حسن عمارة } \\
& \text { باحث دكتوراة بقسم أصول التربية - كلية التربية بقنا - جامعة جنوب الوادي }
\end{aligned}
$$

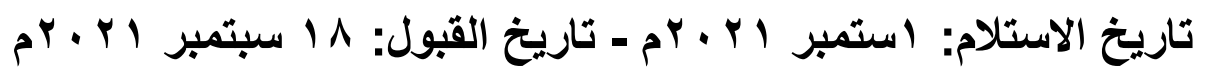

$$
\begin{aligned}
& \text { DOI :10.21608/JYSE.2021. } 187747
\end{aligned}
$$


ملخص :

هدفت الاراسة إلى التعرف على دور المؤسسات التعليمية اللانظامية في تحقيق العدالة

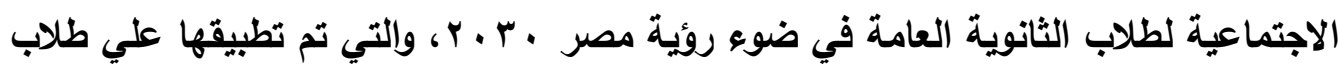

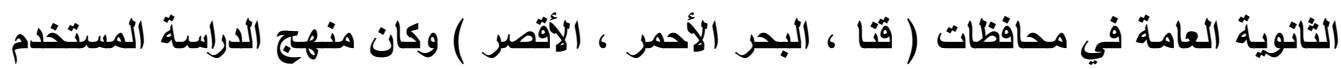

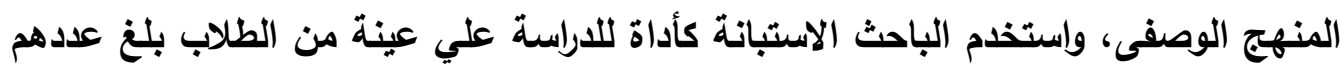
. . . . طالب ، وكان عدد مفردات الاستبانة با مفردة ، ولقد تم استخدام مقياس ليكرت

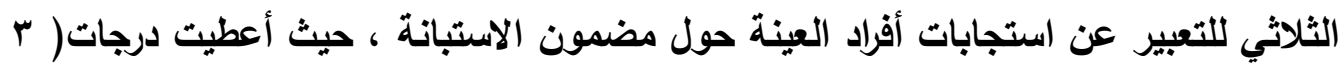

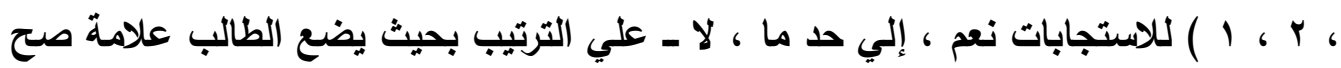

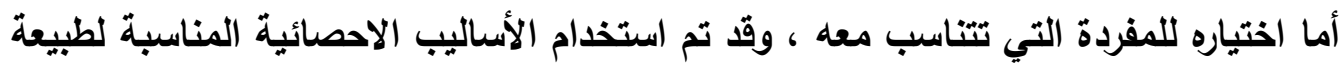

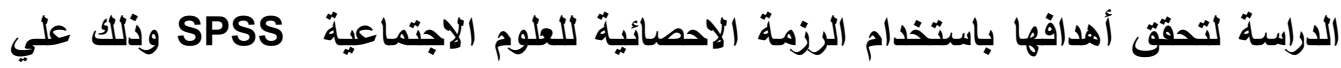

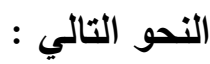
1 ـ حساب النسبة المئوية للتكرارات : للتعرف علي توزيع استجابات أفراد العينة عن كل مفردة من مفردات الاستبانة

r ـ حساب الوزن النسبي : لتحديد مستوي الموافقة أو الإجابة عن كل عبارة r ـ اختبار مريع كاي : لبيان دلالة الفروق بين تكرارات أفراد العينة استجابات أفراد العينة

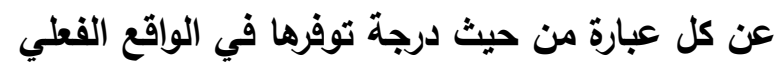

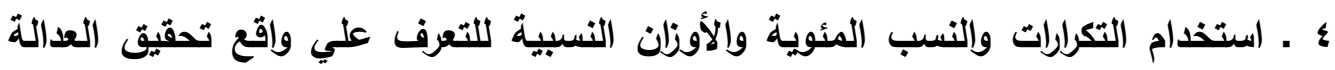

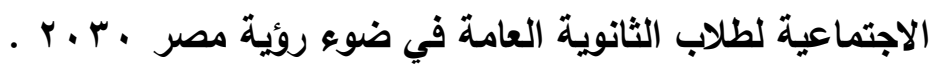
وتوصلت الدراسة إلي بعض النتائج منها : عدم تحقيق العدالة الاجتماعية لطلاب الثانوية العامة مما أدي إلي مشكلات تعليمية ، وصحية ، اجتماعية ، مما يعوق القدرة علي تحقيق

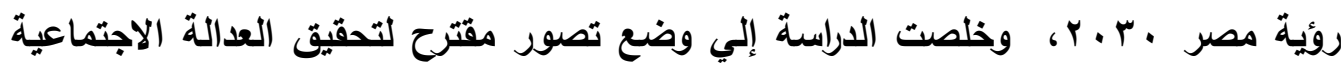

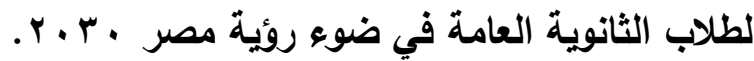
- الكلمات الافتتاحية: المؤسسات ، العدالة ، الروئية. 
The study aimed to identify the role of informal educational institutions in achieving social justice for high school students in the light of Egypt's vision 2030, which was applied to high school students in the governorates of (Qena, Red Sea, Luxor) and the study curriculum was descriptive approach, and the researcher used the questionnaire as a tool for the study On a sample of $\mathbf{3 0 0}$ students, the number of questionnaire items was 63, and the Triple Likert scale was used to express the responses of the sample members about the content of the questionnaire, , where degrees $-3,2,1$ were given to the responses yes, to some extent, no - in order so that the student puts a correct mark as for his choice of the singular that suits him, and statistical methods appropriate to the nature of the study were used to achieve its goals using the statistical package for social sciences SPSS This is as follows:

1) Calculating the percentage of repetitions: to identify the distribution of the responses of the sample members for each item of the questionnaire

2>2 Calculation of the relative weight: to determine the level of approval or answer for each statement

3>Chi-square test: to show the significance of the differences between the frequencies of the sample members, the responses of the sample members to each statement in terms of their availability in actual reality.

4>Using frequencies, percentages, and relative weights to identify the reality of achieving social justice for high school students in light of Egypt's 2030 vision

The results resulted in the failure to achieve social justice for high school students, which led to educational, health, and social problems, which impeded the ability to achieve Egypt's vision 2030 key words:

Institutions, justice, vision. 
خلق الله الكون والطبيعة وسخر ما فيها لخدمة الإنسان ليعيش فيها بطمأنينة وسعادة ،

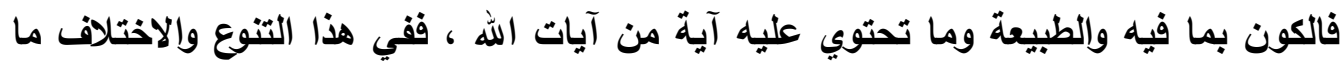
هو إلا دليل علي عظمة الخالق ، ويعتبر الإنسان جزعًا من هذا الكون وله الحق في التنعم الته

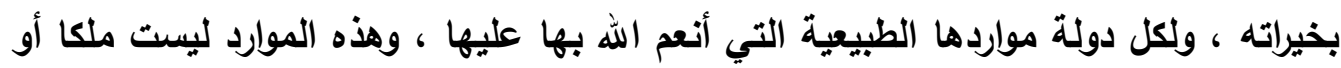

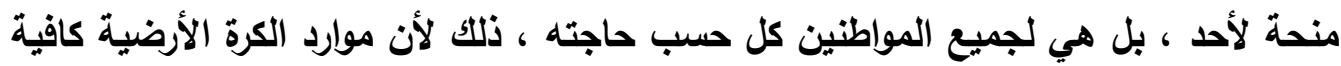

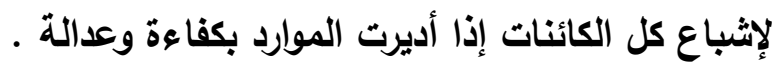
إن تطور المجتمع وتقدمه يبلأ بتوفير كافة الاحتياجات الأساسية من التعليم والصحة

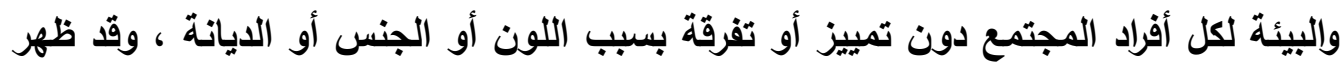
ذلك في جميع الحضارات والثرائع السماوية . وللبيئة الاجتماعية دور كبير في تنشئة الإنسان وتوجيهه والإشراف علي سلوكه ، وتهية وتلقينه ما توصلت إليه من ثقافة وتحضر ، إذ أنها لا تقتصر علي أن توفر له حاجياته الضرورية ، ولكنها تؤدي لله أهم وظيفة وهي وظيفة نقل التراث الاجتماعي والثقافي.) الخشاب : ص ه PV ) وهذه البيئة الاجتماعية تتضمن المؤسسات التعليمية كافة ـ مما يعني بيان أهمية التربية والتوجيه في كل مجتمع وذلك عن طريق التأثير والتأثر العملي الفعال في الأطفال والثباب بواسطة الجهات التعليمية والتوجيهية المتكاملة ، وهي الأسرة في المنزل ، والمجتمع العام في البيئة الإنسانية ووسائل الإعلام المختلفة والأندية الرياضية والثثافية في

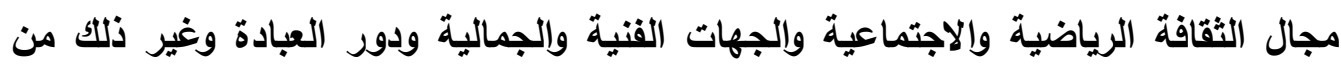

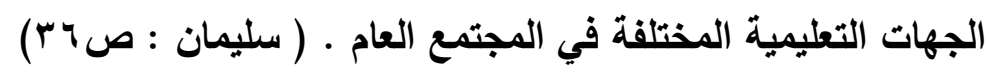
هذه المؤسسات التعليمية اللانظامية مفوضة من قبل المجتمع في تعليم أبنائه ،متمثلة في ذللك أهداف التربية الإنسانية والتي تهوف إلي الوصول للمجتمع البشري الواحد، الذي يبني علي مبادئ العدل والمساواة والحرية ، ويستتد علي قواعد الإخاء والمحبة والتعاون بين أبناء المجتمع الإنساني ، فإن النتائج كفيلة بأن تحرر المجتمعات البشرية من مظاهر التميز وعدام المساواة في الحقوق ، وهي بالتالي تستهدف تسهيل عملية مساعدة الإنسان في بناء المجتمع الإنساني حسب إمكاناته ومسؤولياته ، وعبر التواصل الإنساني القائم علي هذه

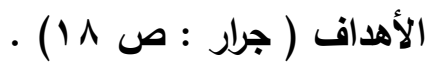


إن العدالة الاجتماعية ، كقيمة إنسانية ومطلب اجتماعي ، قديمة قدم وجود الإنسان

علي هذه الأرض ، إلا أن الحديث عنها والمطالبة بتطبيقها وتحقيقها هو الحديث نسبيا .

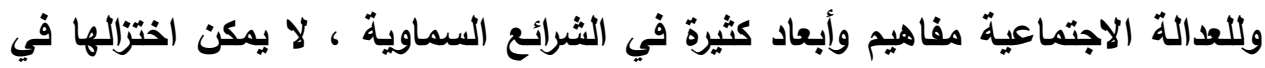
سياق معين بل إنها تشتمل علي كل مناحي الحياة ، إن المعاناة واللا مساواة أو التهميش والحرمان جميعها أتت بفعل البشر ، ولم تتمكن الطبيعة من الحد منها ،. فما كان من الإنسان إلا البحث عن العدل ، ومع تقدم الوعي الإنساني أصبح مفهوم العدل ينفصل عن المجرد ، ويكتسي طابعا ماديا ـ ( الإبراهيم : https://www.raya.com وقد تطور مفهوم العدل باية من القرن الثامن عشر ، فأصبح يهتم بواقع الإنسان ، إنمان

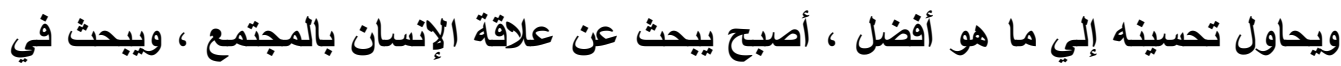
وجوده ، ويفكر في حريته وحقوقه ، فتم الانتقال من مفهوم العدل إلي العدالة الاجتماعية كتصور شامل لحياة الإنسان ولظروف معيشته علي مختلف المستويات . ( الإبراهيم : - (https://www.raya.com و تتفق تعريفات العدالة الاجتماعية علي أنها تسعي لتوفير الاحتياجات الأساسية ، وتحقيق المساواة ، وتوزيع الموارد ، وتوفير فرص العمل ، وتكافؤ الفرص بين الجميع ، ومن لهن بين تلك التعريفات، تعريف الأعرجي : العدالة الاجتماعية مفهوم يشير إلي المساواة في تطبيق الأحكام والقوانين علي الجميع بالتساوي في سبيل تحقيق الصالح العام ، وتصنف إلي عدالة توزيعية ، أي توزيع موارد المجتمع علي الأفراد مع مراعاة قدرتهم ومؤهلاتهم العلمية ، ومنح الناس الخدمات التعليمية والتريوية والصحية والترويحية والاجتماعية التي يجب توزيعها بالتساوي • ( الأعرجي : ( https://al-7awza.org ولعل أكبر دليل علي تزايد الاهتمام الدولي بموضوع العدالة الاجتماعية قيام هيئة الأمم المتحدة بتحديد يوم · r فبراير من كل عام ، بوصفه اليوم العالمي للعدالة الاجتماعية ، وذلك بداية من الدورة الثالثة والستين للجمعية العامة للأمم المتحدة عام ^ . . ب ، الأمر الذي يؤكد علي الاهتمام الدولي والأهمية التي أصبح ينالها هذا المفهوم وما تتمتع بها هذه القيمة التها الإنسانية والمطلب الإنساني الدائم . 
وتناول مفهوم العدالة الاجتماعية العديد من المفاهيم مثل تكافؤ الفرص في الحقوق ،

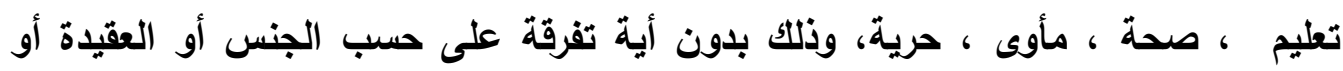

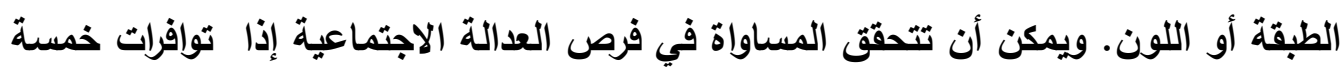
شروط

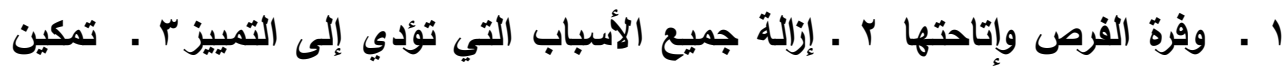

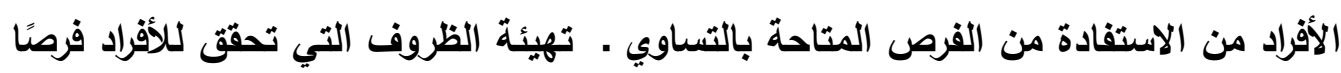

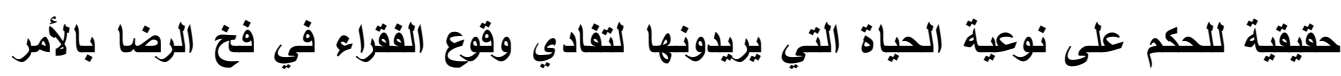

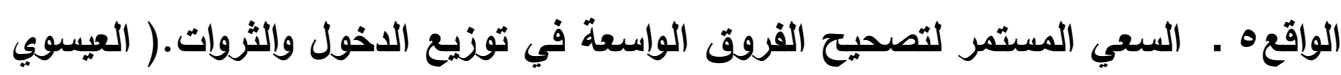

$$
(r \cdot r, r+1 r:
$$

وقد لاحظ الباحث ندرة الدراسات في هذا المجال ولكن يمكن التعرض (لاراسة عوض ب9 9 9 )، والتي هدفت إلي التعرف علي تطور تطبيق المجانية وعلاقتها بالعدالة الاجتماعية

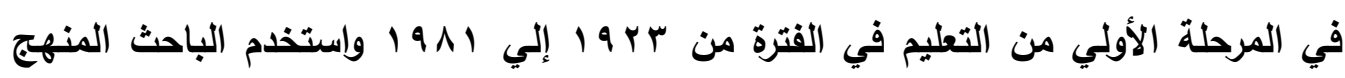
التاريخي ، وتوصل الباحث إلي أنه لم يتم تحقيق العدالة الاجتماعية في هذه الفترة . وكاتت نتيجة ضعف تحقيق العدالة الاجتماعية أن اتجهت الدولة المصرية لتوفئ لتلافي الأثار السلبية الناتجة بأن اتخذت من التنمية المستدامة وهي الهدف الاستراتيجي للاول المتقدمة

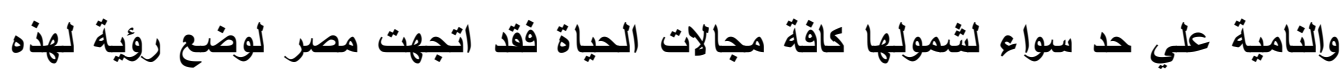

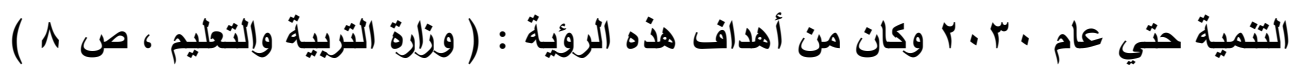
ا ـ القضاء علي الفقر

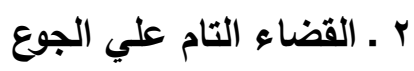
r ـ الصحة الجيدة والرفاهية ع ـ التعليم الجيا ه ـ تحقيق المساواة 
مشكلة الدر اسة:

بالرغم من توالي الثورات الثعبية وما تبعها من جهود حكومية و مجتمعية لتحقيق العدالة الاجتماعية في كافة قطاعات الدولة بصفة عامة وفي التعليم بصفة خاصة، إلا أن هناك العديد من مؤشرات عدم اتساق ميزان العدالة الاجتماعية في مصر؛ والتي كانه وانت نتيجة

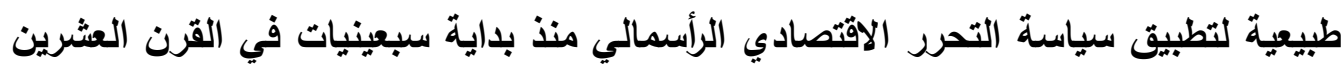

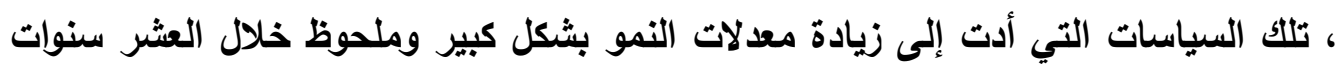
الأولى من القرن الحادي والعشرين إلا أنه وإكبها عدة تأثيرات سلبية على العدالة الاجتماعية

عامة والتعليم بشكل خاص • ( الجعفراوي : ص r r r ) )

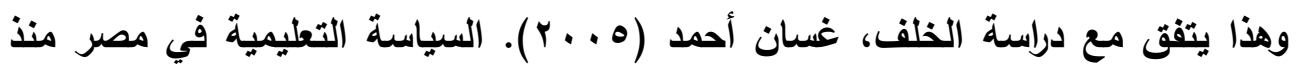
السبعينيات دراسة تحليلية في ضوء مفهوم العدالة الاجتماعية، والتي توصلت إلي عدة نتائج منها : أن السياسة التعليمية في مصر أدت إلى تحسين نسب الاستيعاب والخدمات التعليمية ومضاعفة حجم الإنفاق والمناخ المدرسي، إلا أن هذا التحسن لم يحقى العدالة الاجتماعية المطلوية وفقا للمعايير المجتمعية و الدولية . ولقد تقلصت نسبة الإنفاق العام على التعليم بوجه عام من الناتج المحلي الإجمالي من

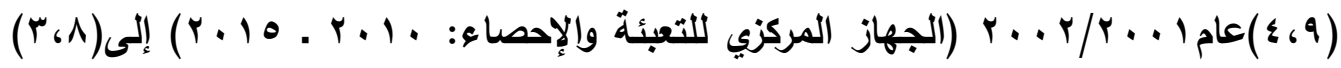

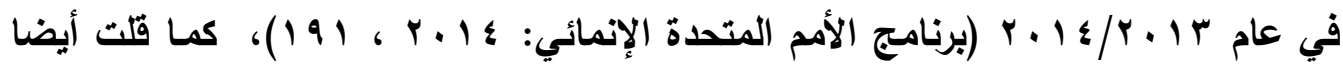

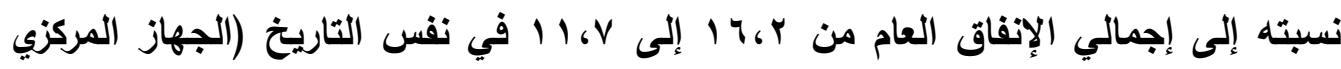

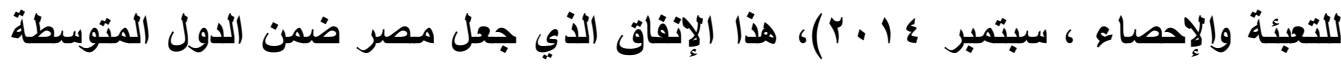

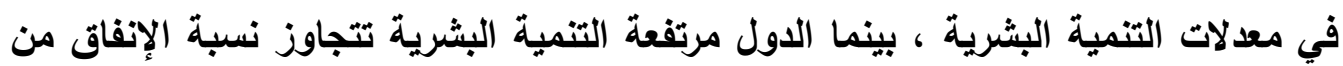

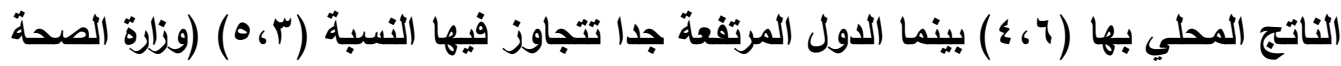
والسكان : بr (19)

ويالنسبة لمعدل الا لتحاق بالتعليم الثانوي فقد بلغ عام \& 1 ـ ب نسبة (VV،V)، وقا وجد تفاوت في معدل الالتحاق في محافظات الوجه البحري عن محافظات الوجه القبلي ثم

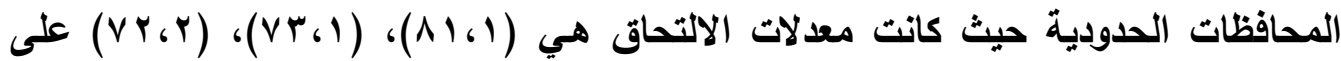
الترتيب ، كما وجد تفاوت بين معدلات الالتحاق وفقا لمؤشر الثروة؛ حيث بلغ معدل الالتحاق

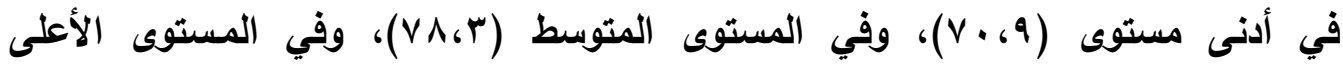


(1،،9)، ما ظهر أيضا تفاوت في معدلات الالتحاق بدرجة بين الذكور والإناث حيث بلغت

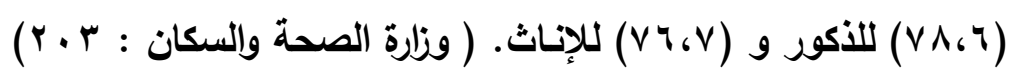

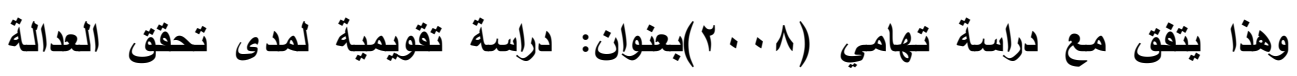

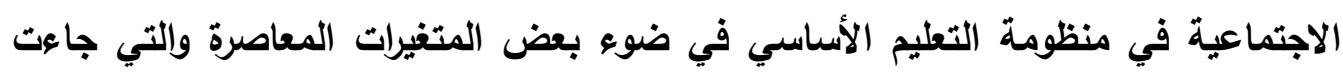

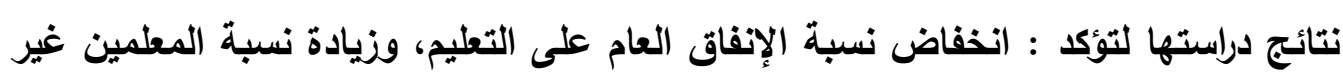

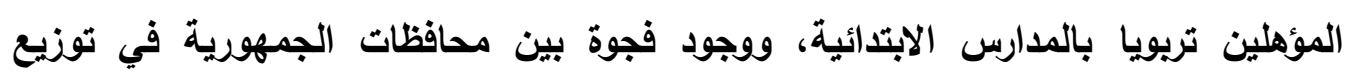
المدارس الخاصة والتجريبية . وإذا كان هذا هو حال التعليم الرسمي أو النظامي فما دور المؤسسات التعليمية اللانظامية

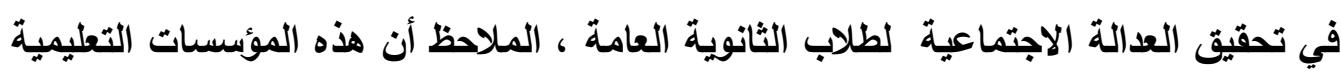

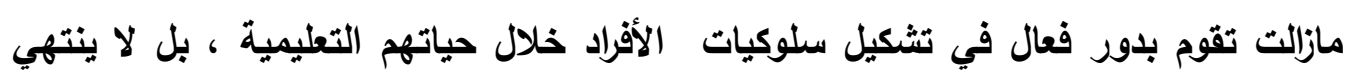

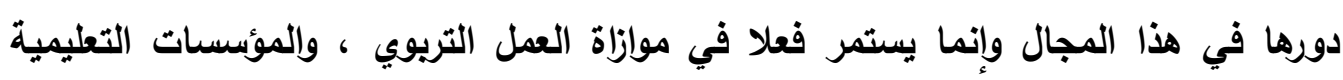

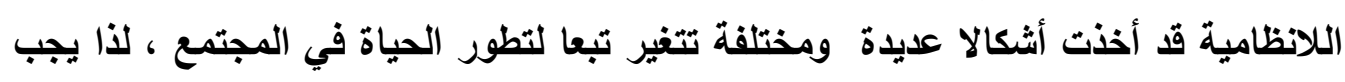

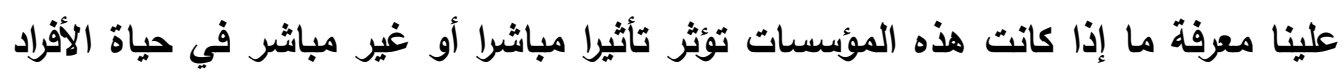

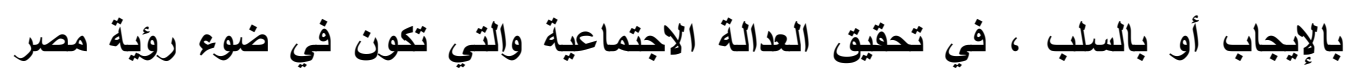

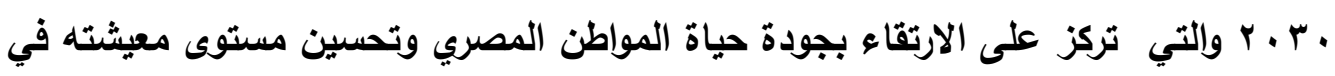
مختلف نواحي الحياة وذلك من خلال التأكيد على ترسيخ مبادئ العدالة والاندماج الاجتماعي الأي

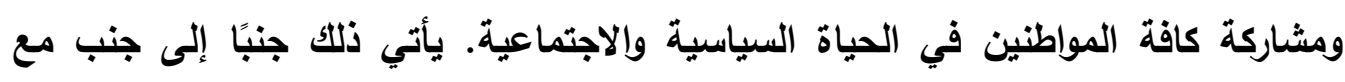

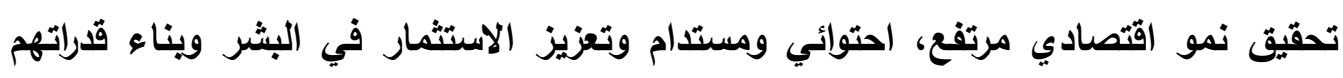
الإبداعية من خلال الحث على زيادة المعرفة والابتكار والبحث العلمي في كافة المجالات.

( https://www.sis.gov.eg/Story لذا كان سؤال الدراسة الرئيس : ما دور المؤسسات التعليمية اللانظامية في تحقيق العدالة

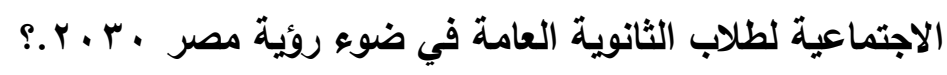

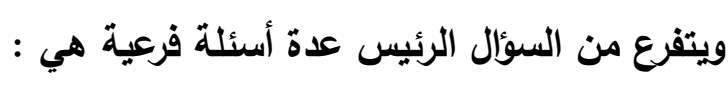

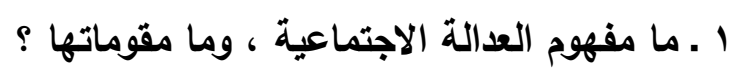

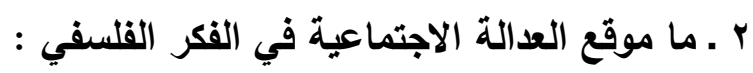
r ـ ما علاقة المؤسسات التعليمية النظامية بالمؤسسات التعليمية التلانظامية التئية 
دور المؤسسات التعليمية اللانظامية............

؛ . ما التصور المقترح لتفعيل دور المؤسسات التعليمية اللانظامية في تحقيق العدالة

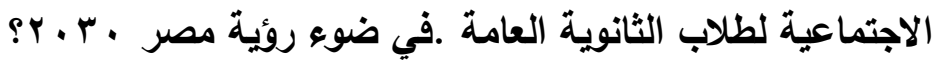
أهداف الدر استة: ا ـ التعرف علي واقع المؤسسات التعليمية اللانظامية في مصر .

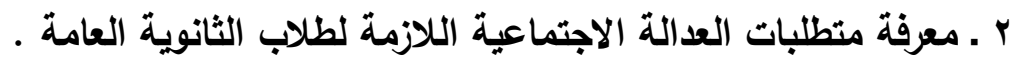

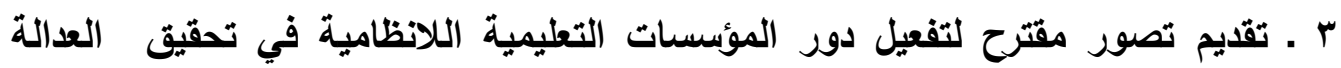
الاجتماعية لطلاب الثانوية العامة - أهمية الدر اسة:

ا - قد تقيد هذه الدراسة فى معرفة جوانب القوة والضعف للشعب المصري مستقبلاً . r. تفيد الاراسة كل من الأسرة ، والإعلام ، ودور العبادة في كيفية التواصل وتحقيق العدالة

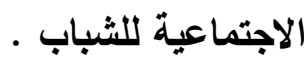

r ـ تتناول الدراسة مرحلة تعليمية على قدر كبير من الأهمية ، وهى المرحلة الثانوية ، وما تمثله فى إكساب الطلاب المهارات الاجتماعية التى تحدد ملامح الشخصية المصرية.

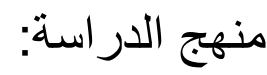
اعتمدت الاراسة على المنهج الوصفي لمناسبته لطبيعة الدراسة الحالية حيث يُعد المنهج

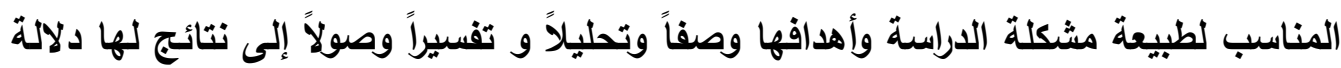

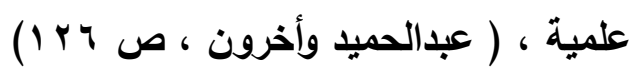

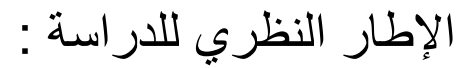
يتناول الإطار النظري للاراسة الحالية المحاور الآتية: المحور الأول : العدالة الاجتماعية: - أولا: مفهوم العدالة الاجتماعية : تعددت تعريفات العدالة الاجتماعية بين الباحثين والمهتمين ، إلا أن جميعها تتفق في

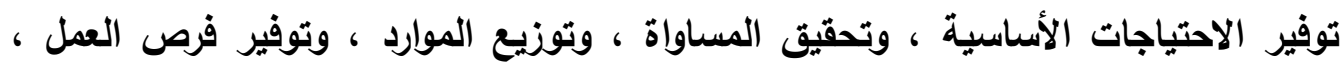
وتكافؤ الفرص بين أفراد المجتمع ، فيمكن تعريفها : ا. العدالة الاجتماعية ، تعني إعطاء كل مواطن حقه في المجتمع وتوزيع الموارد والفرص لهر علي المواطنين بالعدل ، وتوفير الاحتياجات الأساسية لكل المواطنين ، بالإضافة إلي 
المساواة في الفرص ، مثل فرص العمل والتعيين والترقي في الوظائف . ( كبة :

\section{( iraqicparchives.com/}

ويري الباحث أن العدالة الاجتماعية هي نظام اقتصادي اجتماعي يهذف إلي توفير

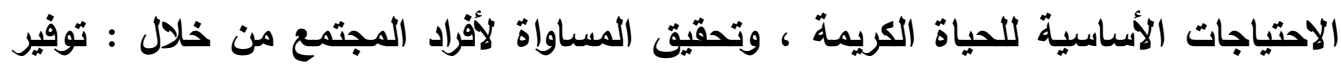

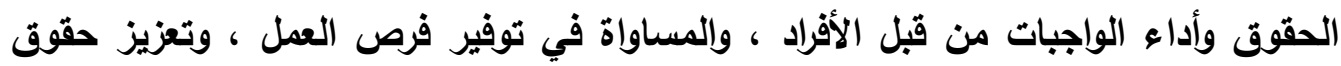

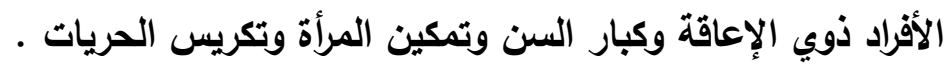
والتعريف الأخير يتفق مع ما أكده المؤتمر الإقليمي للسكان والتنمية في الدول العادئ العربية

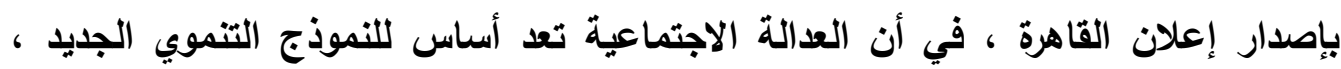
ولكن يجب أن يكون شاملا ومرتكزا إلي مبادئ العدالة والمساواة والإنصاف والحقوق

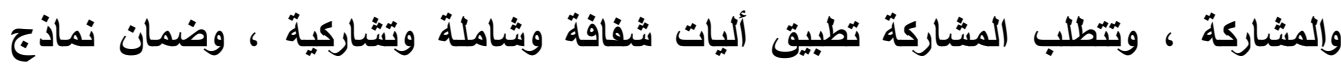
لمشاركة المواطنين في إعادة هيكلة وإعادة تصميم السياسات ، وهذا سيسمح بتحقيق نتائج

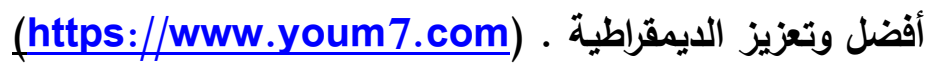
ثانيا: مقومات العدالة الاجتماعية يري الباحث أن العدالة الاجتماعية تقوم على عدة مقومات رئيسة تضمن لها التحقق إجرائيا على أرض الواقع. وهذه المقومات هي: الأول: الإيمان بمبدأ العدالة الاجتماعية، والإيمان بالنظرة للعدالة الاجتماعية على أنها قيمة سامية ومثل أعلى وهي مطلب المجتمعات ومرادها، وطريقها نحو الاستقرار والرقي والتقدم . الثاني: الحقوق التي تضمنها الدولة لشعويها ، وتضم منح كل ذي حق حقه ورد المظالم إلى أهلها، فرد الحقوق لأصحابها ركن رئيس من أركان العدالة الاجتماعية تتتفي وجودها بعد وجود هذا الشرط، وهي نوعان. اما حقوق رئيسة ، وهي حقوق المواطنة، وهي حق لهن لكل مواطن، مثل حق التعليم وحق الضمان الاجتماعي وغيرها، والحقوق التي تكون مقابل نشاط

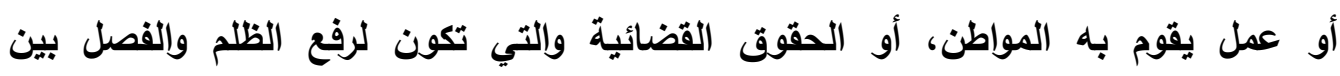
المتخاصمين. الثالث: الواجبات المفروضة على المجتمع، فلا معنى للعدالة في غياب ضمان الواجبات التي تكون بين الأفراد مع بعضهم البعض وتجاه المجتمع، فحتى يكون المجتمع منتجا و مستقرا و منظورا بما يعود بالفائدة الكاملة عليه فإن على أبناءه ومؤسساته الالتزام 
بواجباتهم تجاهه، ومن هذه الواجبات المفروضة : الدفاع عن الوطن، واجب العمل، والتعليم وتتمية القدرات، وواجب الحفاظ على الصحة العامة .. وغيرها، وفي المقابل يجب على الدولة الدئ أن تلتزم بتوفير الفرص الكاملة لأبنائها ليستطيعوا أداء واجباتهم نحو وطنهم . الرابع: الحريات المنضبطة، فضمان هذه الحريات يعتبر الضمان لتحقى العدالة الاجتماعية وغياب هذه الحريات يعني إتاحة الفرصة للتجاوز والتعدي عليها، فالحرية كما هو معروف حق من حقوق الإنسان وهذا الحق يمثل المبدأ الأول من مبادئ جون رولز في روئه للعدالة الاجتماعية، ويظل تحقيق العدالة الاجتماعية مرتبط بتحقيق الحريات الرئيسة لكل أبناء المجتمع وتوسيعها بما يساعد كل فرد من اختيار نوع الحياة التي يعطيها قيمة، ( العيسوي :

الخامس: المشاركة المجتمعية، فالعدالة الاجتماعية تعد مسئولية مشتركة للاولة والمجتمع معا، فلا يمكن تحقيق العدالة الاجتماعية إلا في إطار وجود دولة يتساوى فيها الجميع أمام القانون ، ويكون واجب النظام هو العمل على تحقيق التوازن بين الجميع و العدالة بين

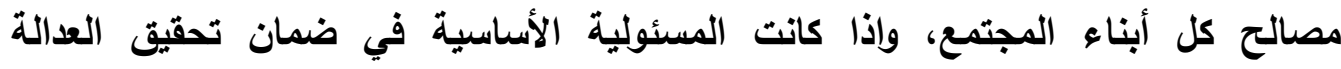
الاجتماعية تكون على الدولة ومؤسساتها الحكومية، إلا أن المجتمع بأبنائه ومنظماته

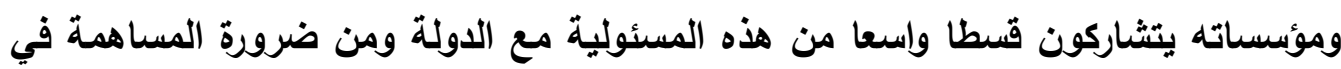

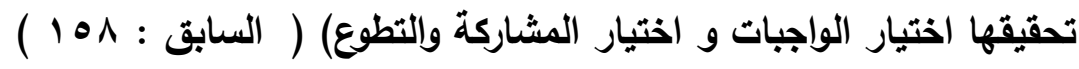
ثالثا : الأبعاد والإثكاليات: تشير إمكانية تحقيق العدالة الاجتماعية عددا من الإثكاليات يمكن حصرها على النحو التالي:

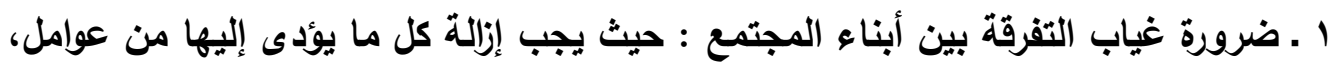
وغياب ما يترتب على التفرقة من نتائج سلبية كالحرمان من الحقوق والإقصاء الاجتماعي. r ـ إثكالية توفير فرص متساوية: حيث لا معنى للحديث مثلا عن المساواة في فرص العمل إذا كانت البطالة منتثرة ومواطن العمل غائبة. r ـ إثكالية التمكين: فلا معنى لوجود فرص اذا لم يرتبط معها استراتيجيات التمكين لجميع

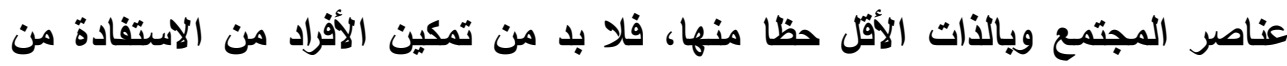
الفرص ومن التنافس على نفس درجة المساواة بينهم من أجل الحصول عليها . 
؛ ـ إثكالية الحظ ووجود الفوارق الفردية: فقد يظهر الاختلاف في قدرات الأفراد وفى نصيب

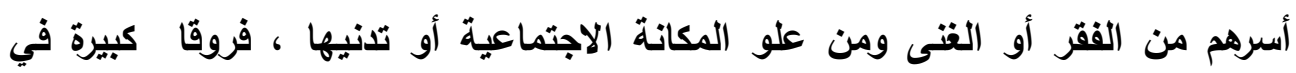
العوائد أو النواتج تتجاوز ما يمكن اعتبارها فروقا مقبولة اجتماعيا ، ومن هنا تتضح ضرورة تلخل الدولة بسياسات إعادة التوزيع لتقريب الفروق في الدخل والثروة بين

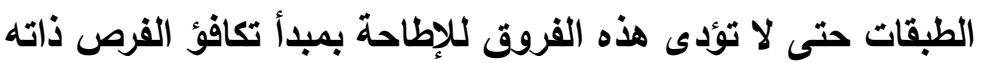

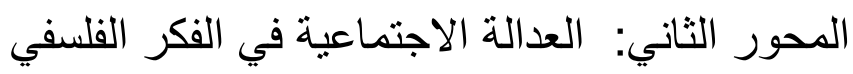
مفهوم العدالة الاجتماعية مفهوم يتصف بالقدم حيث شغل اهتمام الفلسفة القدامى الذين اهتموا بوضع شكل للعلاقة بين الثعوب وحكامها، ويمكن تصنيف هذا الفكر الفلسفي وفق روئيته الاجتماعية للمجتمع إلى نوعين لونين I ـ فكر أرستقراطي طبقي يؤمن بالطبقية المجتمعية ويؤصل لها. r ـ فكر تحرري ليبيرالي ينكر هذه الطبقية ويدعو للتحرر منها.

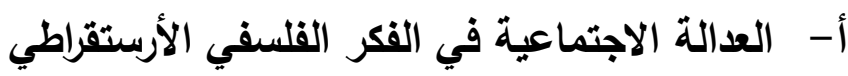
بالنظر إلى الحركة القلسفية في بالياتها الأولية يتضح أنها كانت تنظر نظرة طبقية للمجتمع وتؤيدها وتبرر لها، ومن أشهر الفلاسفة في ذلك الوقت الفيلسوف اليوناني أفلاطون

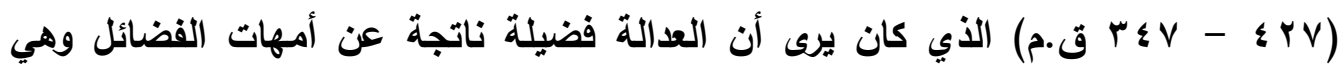
فضيلة ( الشجاعة و الحكمة والعقل ) فيجب على كل إنسان التكيف مي هذا النظام من

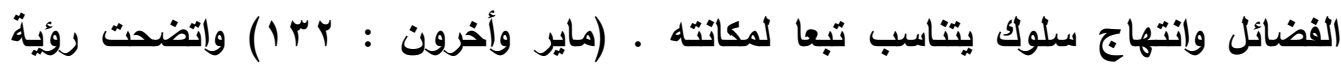
أفلاطون هذه عندما وضع في كتابه الشهير الجمهورية حيث كانت روئة مثالية أرستقراطية متفرقة بشكل ملحوظ عن واقعه الذي عاشه في دولة أثنيا، حيث قام بوضع تصور للاولة أو المدينة المثالية التي يجب أن تتحقق فيها العدالة وذلك بالقيام بعملية ريط بين الطبيعة التي لتي تحكم الإنسان ويين مكونات الدولة، فأفلاطون يرى أن المجتمع يتكون من ثُلاث طبقات

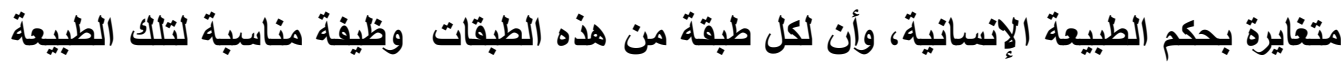
، حيث حدد لكل طبقة منها فضيلة تتناسب مع طبيعتها، فحين تختص طبقة الحراس بفضيلة

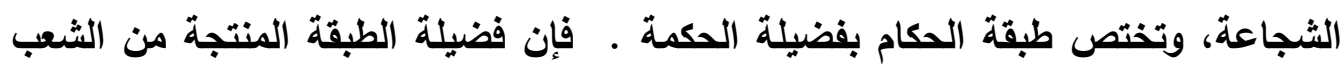
هي التحكم في الثهوة، هذه الفضائل الثلاث هي التي يجب توافرها في طبقة الثعب حتى يمكن تحقيق العدالة في الدولة . بشرط أن يتجه كل إنسان في الدولة للوظيفة التي منها له له 
طبيعته دون أن يتدخل فرد من طبقة في مهام ووظائف الطبقة الأخرى حتى لا تنتهي العدالة

وينتشر الظلم. ( مطر : ص 17 )

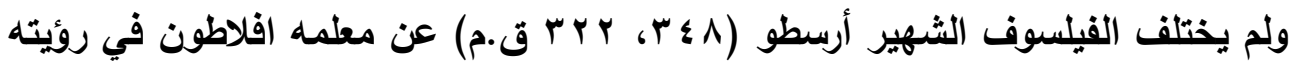
الفلسفية للعدالة الاجتماعية، حيث قسم الناس إلي صنفين ( إلي أحرار و عبيد ) وذلك وفقا لطبيعته الإنسانية، وأكد أن بعض هؤلاء الناس قد خلقوا أحرار مؤهلين عقليا وجسمانيا للحكم وللإمارة والبعض الأخر منهم قد خلق عبدا أهلته الطبيعة الجسمية فقط للطاعة والقيام بالأعمال المتعبة والثاقة بل ويرر أرسطو لنظام الرق واعتبره أمرا طبيعيا وعدلا ( عبدالعال :

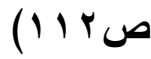

إلا أن أرسطو في نظرته الأرستقراطية هذه ، ق ميز بين صنفين من العدالة. الأول: العدالة التعويضية وهي تقديم تعويض للأشخاص الذين يختلفون بطبيعتهم وإن كانوا يتساوون في الحقوق القانونية بينهم. ( ماير وأخرون : بr I ) حيث يعتبر التعويض في هذه الحالة عدلا إذا وجلت مساواة حقيقة بين أطراف التعويض وكانت لهما ذات القيمة واتئ، ومنها مثلا تعويض المظلوم من الظالم كأن يكون ذلك في المعاملات أو الجرائم وغيرها ـ ( سعيد : (r أما الثاني: وهو العدالة التوزيعية وتسمي عدالة (التقسيم) وهي تنظيم العلاقة بين واجبات الدولة والمجتمع تجاه أعضائها في إطار مبأ الحقوق والواجبات وبين واجبات الفرد تجاه المجتمع وهي تتمثل في توزيع موارد الدولة وما تتتجه على أفرادها حسب الاستحقاق، باعتبار أنه ليس من العدل توزيع ذات المقادير على أشخاص غير متساويين · ( سعيد :

وفي مصر القديمة، صنف المصريون القدامى إلى ثلاث طبقات اجتماعية: الأولي وهي والأوسع نفوذا وهي طبقة الكهنة، وكانت لهم السلطة الكبرى على الشعب و الفراعنة وأمور الحكم، وكانوا يتصفون بالعلم ويتكلمون لغة خاصة بهم هي اللغة الهيروغليفية ،أما الطبقة وهية الثانية فتضم رجال الجيش من المحاربين الذين كان يطلق عليهم نبلاء، وأما الطبقة الثالثة

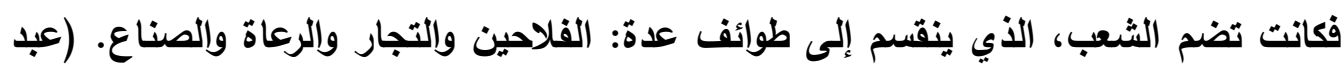

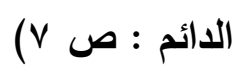




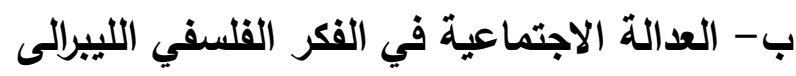

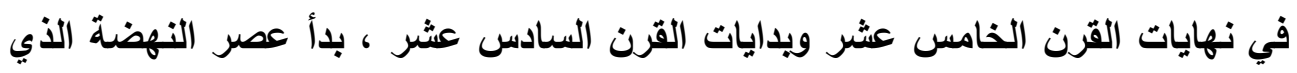
تميز بكثرة الأفكار عن العرية الفردية والمساواة والعدالة الاجتماعية، وارتفعت الكثير من الفئ

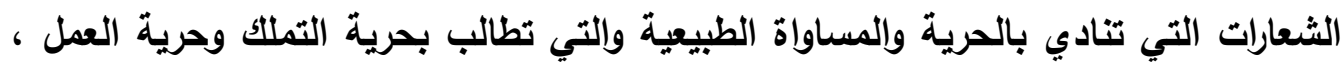

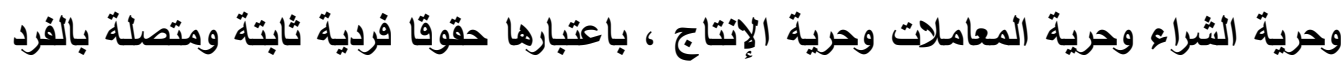

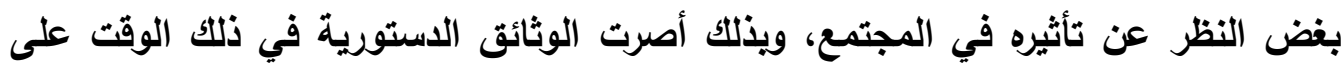

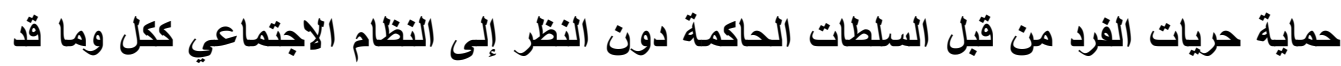

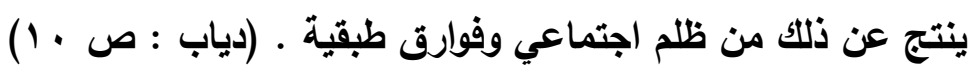

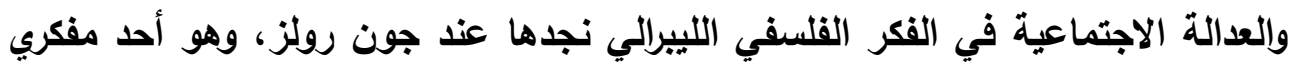
هذا الاتجاه الأين وضعوا أفكارهم وتصوراتهم حول طبيعة العدالة الاجتماعية السياسية بين العاعين

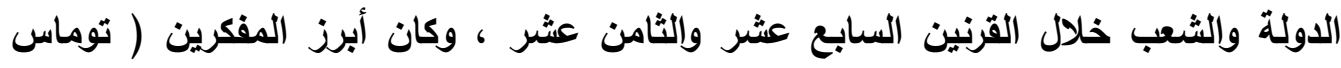

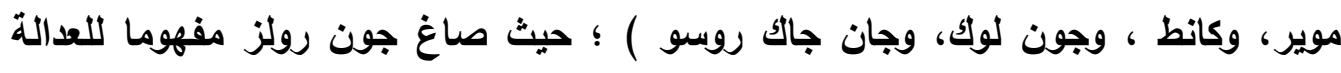

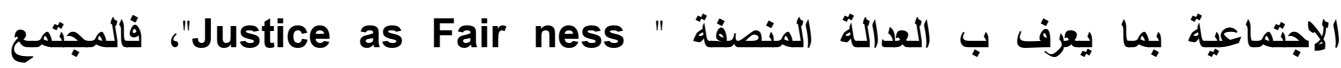

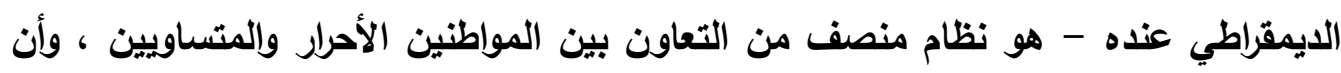

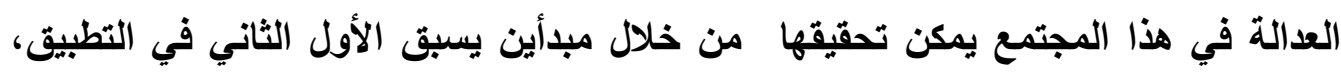

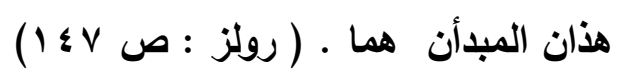

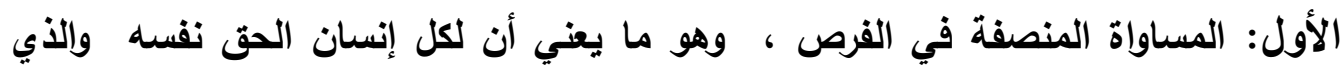

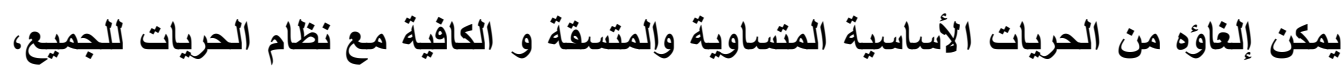

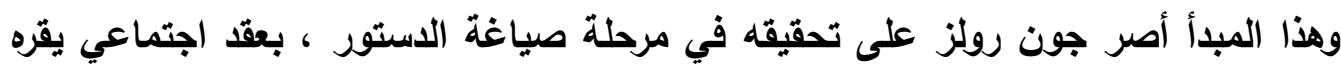

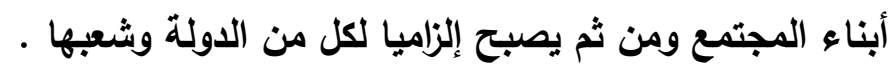
المبلأ الثاني: مبلأ الفرق؛ وهو ينص على أنه يجب إنباء أن تحقق ظواهر عدم المساواة الاقتصادية و الاجتماعية شرطين: أولهما يفيد أن عدم المساواة يجب أن تتعلق بالوظائف الهائ

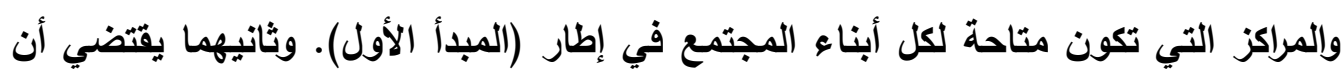
تكون ظواهر عدم المساواة محققة أكبر مصلحة لجميع أبناء المجتمع ويخاصة الأقل مركزاً.

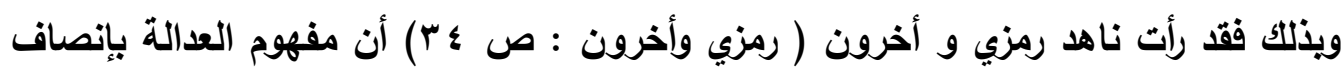
كما رأها جون رولز به الأبعاد التالية: 
1 ـ أن كل المواطنين لهم حق التمتع بحقوق متساوية في كافة المجالات الاجتماعية و

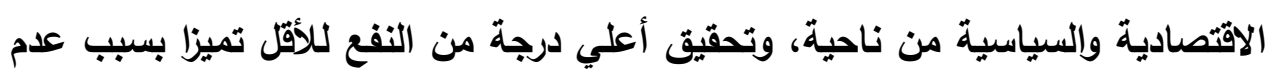

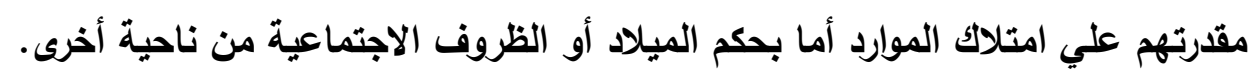

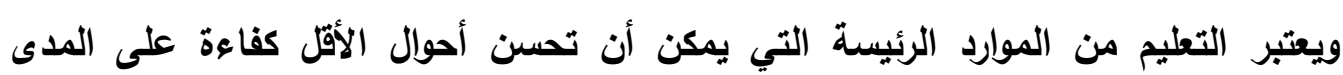
الطويل. تعبل.

r ـ مفهوم العدالة في الإنصاف لا يقتصر على المساواة الثكلية والتي تترجم في المواثيق الحقوقية والدساتير، ولكنه يتناول المساواة الموضوعية، والتي يقصد بها التوزيع العادل للموارد المجتمعية بكافة أنواعها .

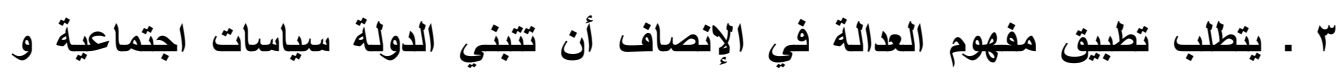
اقتصادية جادة في تحقيق العدالة الاجتماعية.

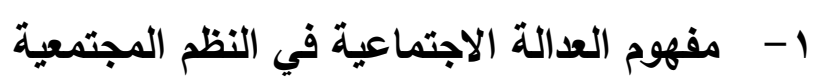
هنات ارتباط كبير بين مفهوم العدالة الاجتماعية وبين النظم الاقتصادية التي تتبناها سياسة الدولة و التي يتكون في ضوئها النظام المجتمعي ككل. ويمثل النظامين الاثتراكي و

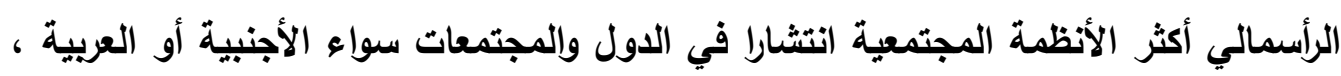
ولكل نظام فلسفته وألياته و مفهومه في تحقيق العدالة الاجتماعية. أ- العدالة الاجتماعية في النظم الاثتراكية: الاشتراكية في هذا التنظيم الاجتماعي الأي تكون فيه وأدوات الإنتاج ووسائله والقرارات الخاصة بكيفية الإنتاج ونوعية السلع التي يتم انتاجها، ومن الذين يحصلون عليها تحت سيطرة الدولة، بدلا من الشركات ذات الملكية الخاصة. بمعنى انتقال وتحويل شئون أفئه أفراد

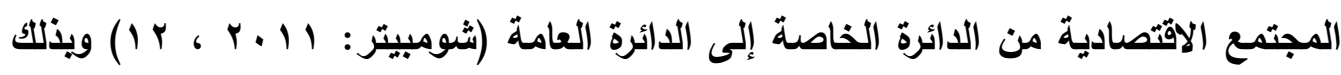
فإن العدالة الاجتماعية وفق مايراه سان سيمون - أحد رواد الاشتراكية - يمكن تحقيقها عندما يحصل الناس على شيء مكافئ ومتساو في القيمة لما يقدمونه (أوحين يقدمون شيئا

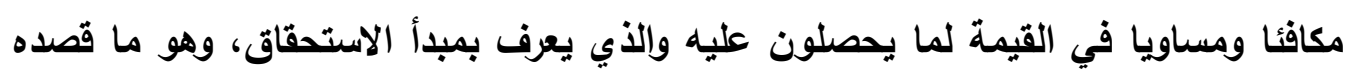
سبنسر - أحد مناصريه - حين وصف المجتمع بأنه مجمتع عادل إذا: يتساوي جميع أبناءه مادام كل واحد من أفراد هذا المجتمع يضمن أن يتمتع بالحرية في نطاق من التصرفات التي 
تقيلها حدود حريات الآخرين وحين تتمثل قيم المكسب والخسارة التي تكون من نصيب أبناء

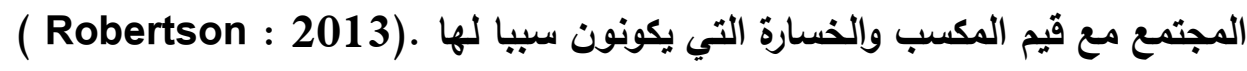
وهي وفق روية لويس بلانك ترتكز على مبدأ - الاحتياج حيث قال : كل بحسب قدرته، ولكل حسب احتياجه"، بمعني أن يتم توزيع الثروة على أساس الاحتياج، وهو ما قال عندئ فيخته: بأن الدولة التي تسعي بتحقيق العدالة يجب أن تضمن توزيع المكاسب على جميع

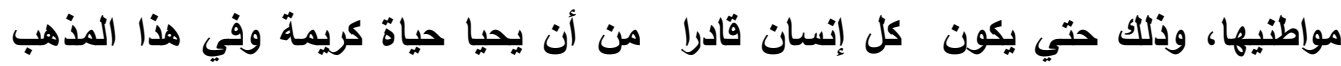

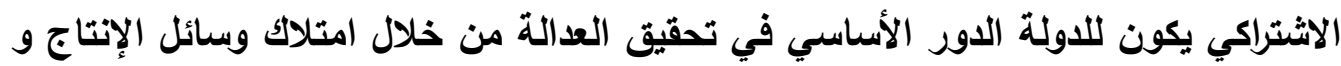

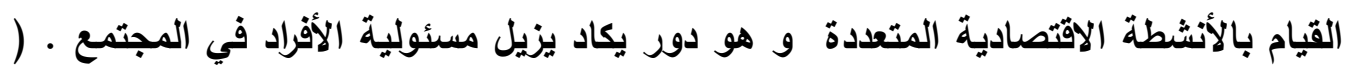

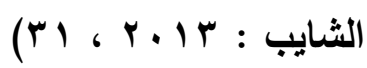
ب - العدالة الاجتماعية في النظم الرأسمالية: عندما تكون ملكية وسائل الإنتاج مقصورة على طبقة بعينها فهذا النظام يسمي ب النظام

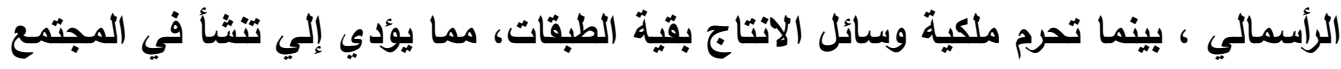
فوارق كبيرة في توزيع الاخل والثروة وهذه الفوارق لا ترتبط بالفوارق بين أبناء المجتمع في

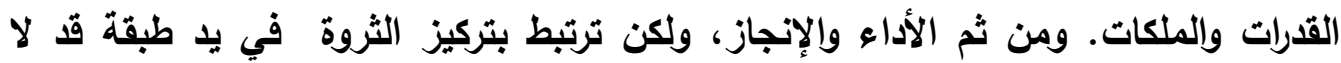
تشكل سوى نسبة ضئيلة جدا الثعب ، هذا من جهة، ومن ناحية أخري يتوارث الثروة

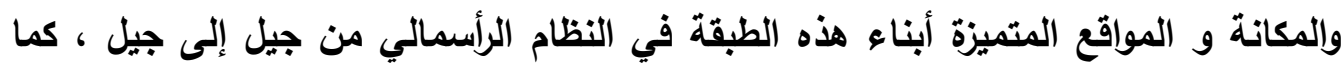
ترتبط هذه الفوارق الطبقية في هذا النظام بظاهرة الاستغلال الرأسمالي المعتمد على استخدام رأس المال للعمل المأجور في انتاج السلع ، لذا ترتبط العدالة الاجتماعية في النظام

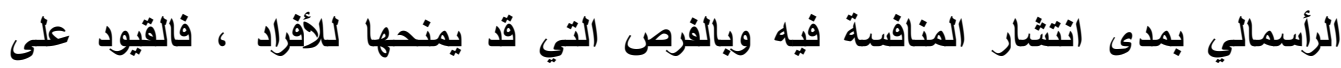
المنافسة تكون نتيجتها تركز المنافع في جماعات قليلة ولا تتحقق بالتالي المساواة ويضيق وياليق

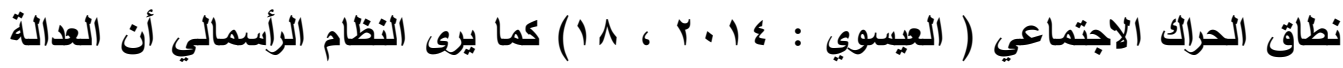
تتحقق وفقا لما يمكن تسميته عرض وطلب السوق ، وهو ما يجعل الطبقات الضعيفة تحت

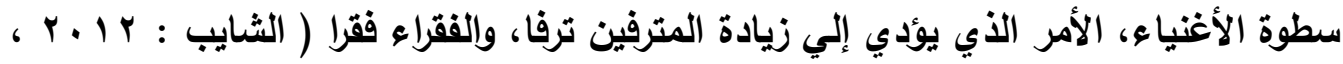
اץT) ويشير رضا سعادة إلي أن الحرية تضمن تحقيق المساواة بين الناس في الحقوق، حتي عندما يوجد فقراء وأغنياء، فإن الفرد حر في الوصول إلى طبقة أفضل، كما هو حر في 
تغيير أوضاعه إلي الأفضل، وعليه فهو يتحمل مسئولية ما ينتج من فشل في استخدامه

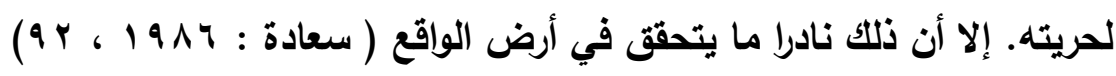

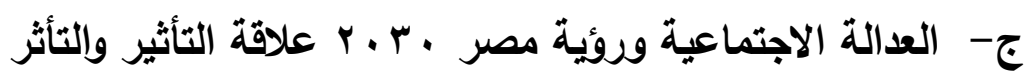

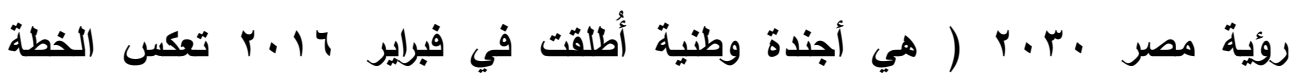
الاستراتيجية طويلة المدى للاولة لتحقيق مبادئ وأهداف التتمية المستدامة في كل المجالات، ولماته

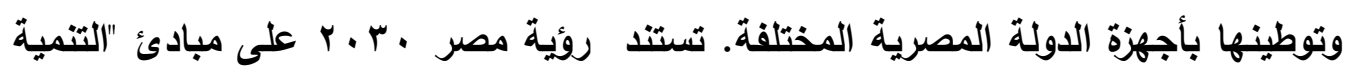

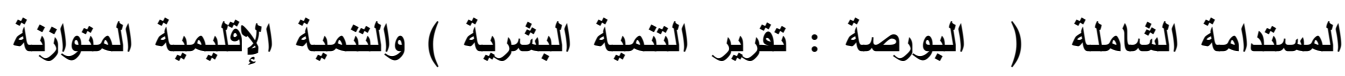

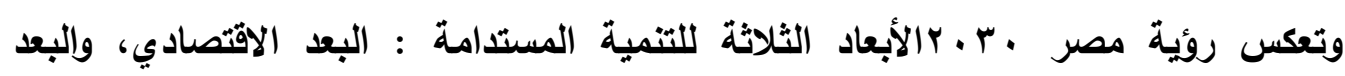
الاجتماعي، والبعد البيئي

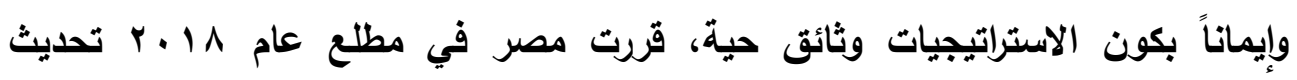

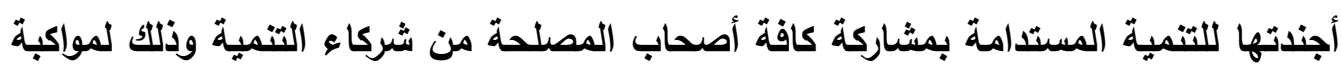
التغييرات التي طرأت على السياق المحلي والإقليمي والعالمي. واهتم الإصدار الثاني لروئية مصر •.r.r بأن تصبح روئة ملهمة تثرح كيف ستخدم المساهمة المصرية الأجندة الأممية، وكيف سيخدم ذلك السياق العالمي. وتؤكد الروئة المُحدثة على تناول وتداخل كل

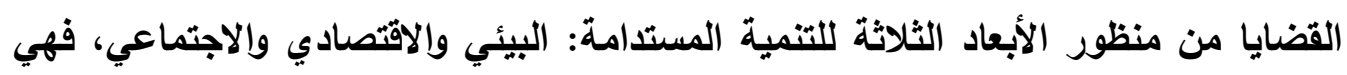
روئية شاملة ومتسقة تتكون من استراتيجيات قطاعية للجهات الحكومية المختلفة.

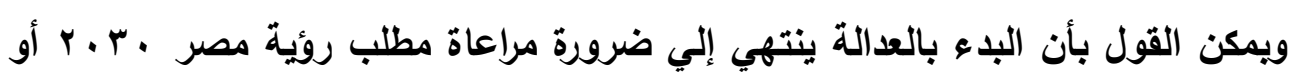

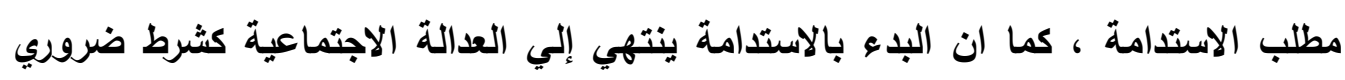

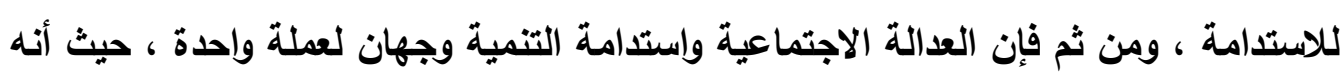
لا تنمية بدون عدالة اجتماعية تحظر التمييز وتوفر الفرص بتكافؤ وتكفل التوزيع العادل

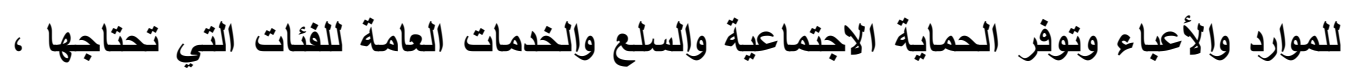
وتراعي العدالة بين الأجيال والمناطق وهو ما يتطلب رسم السياسات الاقتصادية والاجتماعية بما يتلائم مع التقدم المستهدف إحرازه علي طريق العدالة الاجتماعية وإنتفاء أي مبرر لتأجيل مطلب العدالة الاجتماعية ، ومكافحة الفقر إلي حين إنجاز قر واف من النمات النمو الاقتصادي حيث أن الأثر الإيجابي للعدالة الاجتماعية يكمن في وتيرة النمو الاقتصادي ومحتواه 
وتتضح العلاقة بين العدالة الاجتماعية وروئية مصر ، ب . من خلال السعي الائم لتحقيق تكافؤ الفرص والمساواة بين المواطنين ، ولكن يجب ملاحظة ما يلي : 1 ـ العلاقة بين المساواة و العدالة الاجتماعية : كثيراً ما يتم الخلط بين هاتين القيمتين ويتم التناول لهما من قبل البعض كمترادفين. ولكن يجب الحرص إلي أن العدالة الاجتماعية

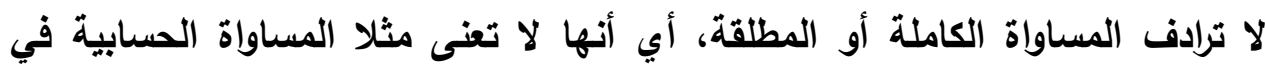

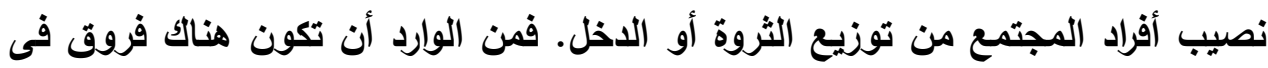
توزيع هذه الأنصبة، حيث تتواكب هذه الفروق مع الفروق الفردية بين الناس فى كثير لترن

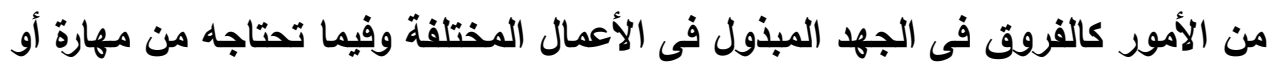

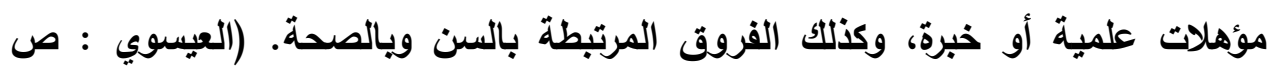

r ـ العلاقة بين الحرية و العدالة الاجتماعية : إن الصلة بين تطبيق العدالة الاجتماعية ومسألة اختلافها مع قيمة الحرية هو نقاش وحوار دائم في مجال الفكر السياسي، حيث

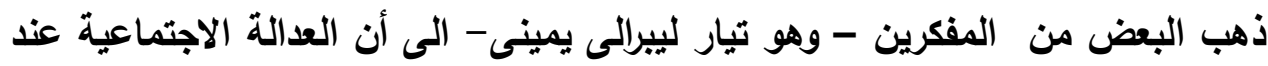

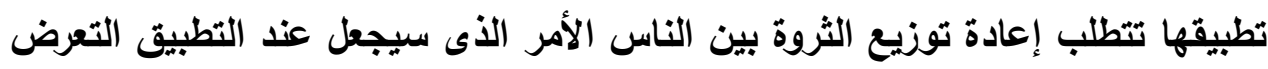

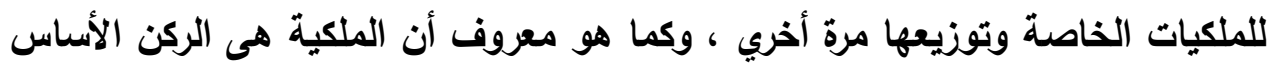

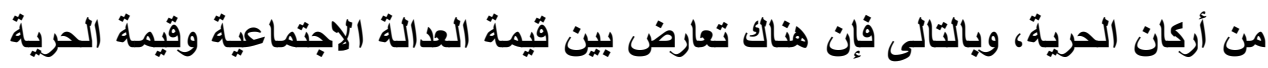

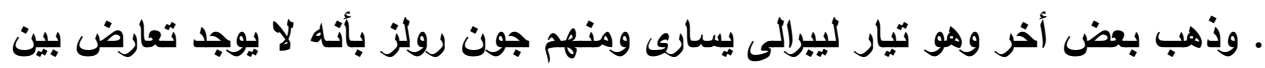
العدالة الاجتماعية وبين الحرية حيث تهدف الأولي إلي إعادة توزيع الحقوق للفقراء

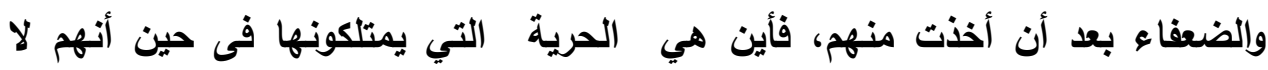

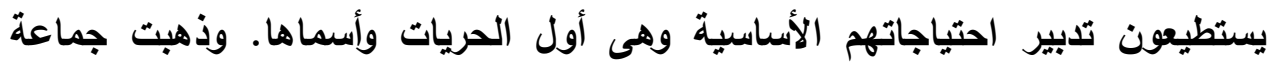
أخري وهو اتجاه اشتراكي، أن الاختلاف جاء بالأساس بسبب الفهر الخاطئ من

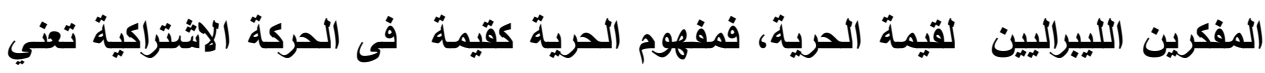

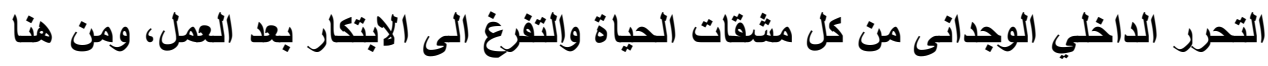
لا يوجد اختلاف بين وجود عدالة اجتماعية وبين تمتع الأفراد بحرياتهم • ( السيف : 
r ـ العلاقة بين التنمية والعدالة الاجتماعية : إذا أرادت الحكومة تطبيق العدالة الاجتماعية في المجتمع فلا بل أن يصاحب ذلك عملية تنمية تثمل كافة الجوانب السياسية

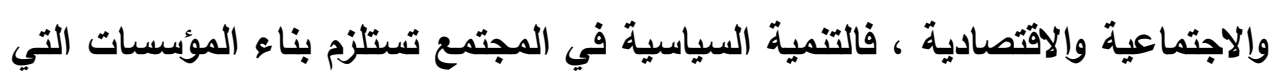
تستطيع استيعاب التغيرات التي تحدث في هذا المجتمع وحشد الرأى العام ومؤسسات

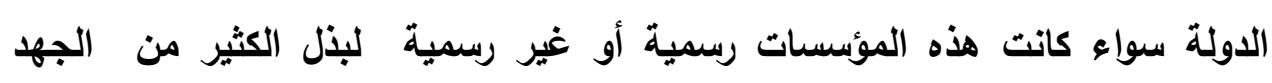

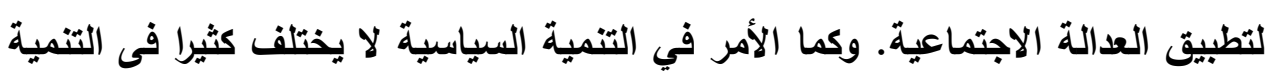

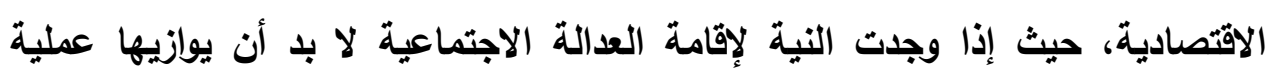

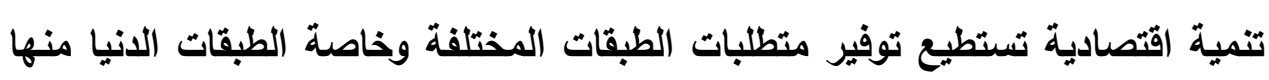

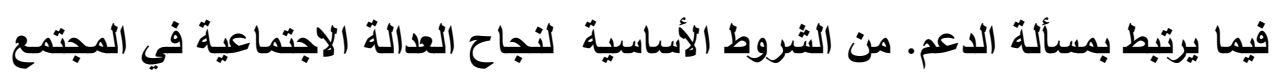
وجود تنمية اقتصادية ليستطيع أفراد المجتمع استيعاب موجات التغيير القادمة.

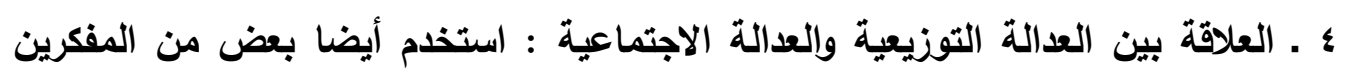

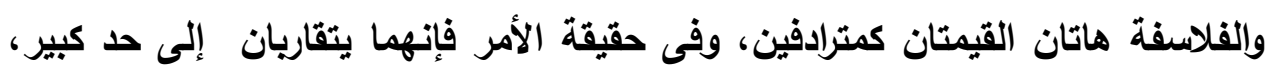
فالعدالة التوزيعية تتمثل في توزيع الحرية السياسية والحقوق الطبيعية والمساواة الاجتماعية بشكل منصف بين أفراد المجتمع، والغرض من عدالة التوزيع هو دفع البنية

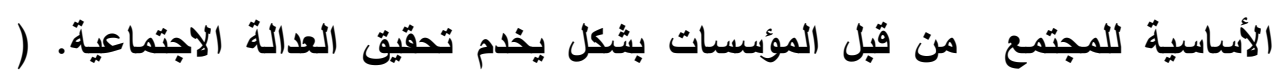

\section{(ttp://www.aleqt.com : السيف}

وتعاني المجتمعات العربية علي ما بينها من اختلاقات في المستوي الاقتصادي والتنموي

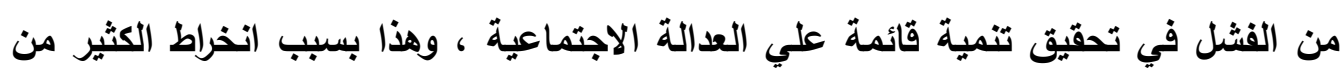
الاول في تطبيق سياسات تكرس التهميش والفقر والإقصاء وعدم المساواة ، إذ يكاد لا تخلو دولة عربية من صور الظلم الاجتماعي والتهميش والتمييز ، وتحقيق العدالة الاجتماعية

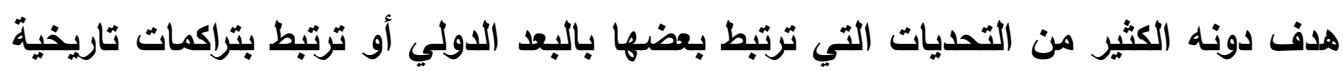

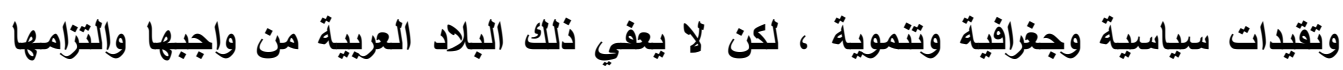

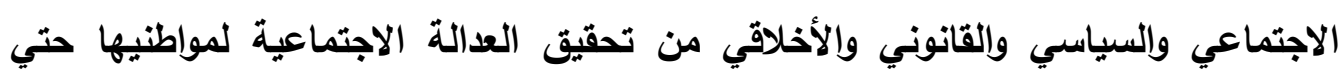
أصبحت شرعية أي نظام للحكم ترتكز علي أساس مدي قدرته علي تحقيق هذه العدالة

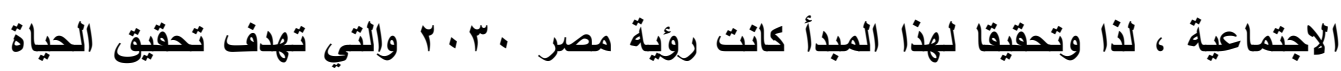
الكريمة للمواطنين في شتي المجالات ـ حيث تكون العادلة الاجتماعية وفقا لهذه الروئية 
أساسا للتمية البشرية المستدامة ، حيث أن قيم العدالة الاجتماعية ماهي إلا نتيجة ظروف

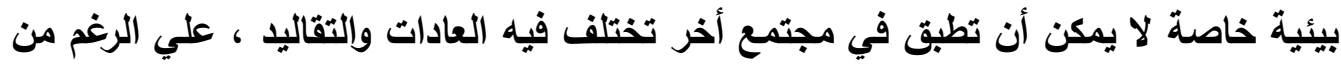
أن مجموع هذه القيم نابع من منطلقات إنسانية ودية لكنها قد تختلف حسب الإمكانيات والحق التاريخية ، ومستوي الوعي الاجتماعي والثقافي لاي أفراد المجتمع ، فيشير مؤثر التنمية البشرية إلي تقييم التقدم الطويل الأمد في ثلاثة أبعاد رئيسة ( البورصة :

(https://mapp.alborsanews.com/

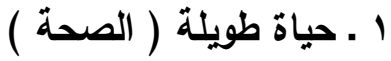

r ـ الوصول إلي المعرفة

r ا ـ مستوي معيشي لائق

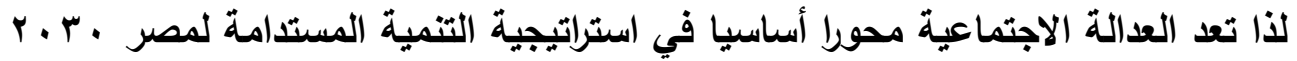
وتذهب الروية إلي أنه بحلول عام ·.r.r تصل مصر إلي مجتمع عادل متكاتف يتميز بالمساواة في الحقوق والفرص الاقتصادية والاجتماعية والسياسية ويأعلى درجة من الاندماج المجتمعي ، قادرا علي كفالة حق المواطنين في المشاركة والتوزيع العادل في ضوء معايير الكفاءة والإنجاز وسيادة القانون ، ويحفز فرص الحرالك الاجتماعي المبني علي القدرات ، ويوفر أليات الحماية من مخاطر العياة ، ويقوم علي التوازي بمساندة شرائح المجتمع المهمشة ، ويحقق الحماية للفئات الأولي بالرعاية .

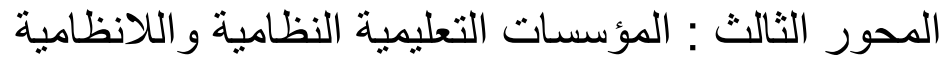
في البداية يجدر الإشارة إلي أن مصطلحي" التربية "و" التعليم "مصطلحان مترابطان، لا وفيه

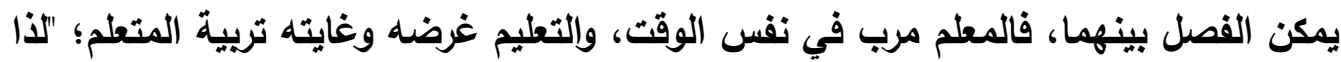
يتعذر الفصل بإطلاق بين مصطلح التربية ومصطلح التعليم، فالتربية إذا ذكرت مع التعليم في مئي سياق واحد، فإن التربية تأخذ معنى العمل القائم على دعائم العلم، والتعليم يأخذ معنى التزويد

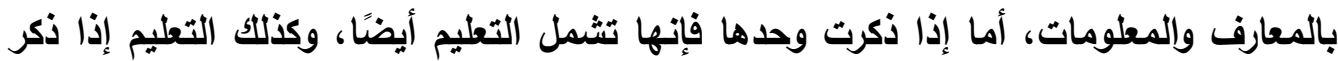

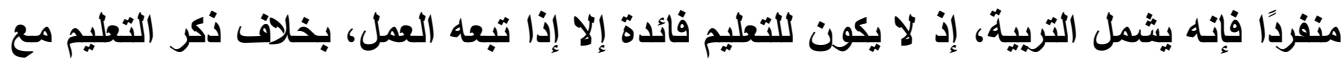
التربية فإنه ينحصر في المعنى المعرفي، فإذا اجتمعا استقل كل مصطلح بمعناه الخاص، وإذا لهال

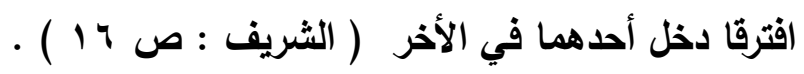

بعد معرفة ذلك التقسيم أو التصنيف الأى جرى بين كثير من المربين والمدرسين وفى المى بعض المؤلفات التريوية بين ما يسمى بالمؤسسة التعليمية النظامية ” والتى تتميز بها 
المدرسة ممثلة فى مناهجها وأساليبها وأنشطتها وقوانينها وأهدافها ويرامجها والمؤسسة

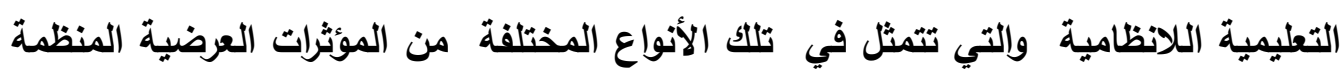
أو غير المنظمة التى تتم دون قصد أو هدف واضح فى سياق حياة الفرد وكيف يتفاعل مع في مئه مختلف فئات المجتمع من حوله وهذا بالطبع لاعلاقة له بالمدرسة وقوانينها وإشرافها

وتوجيهـا

وترتب على هذا التصنيف ظهور العليد من الاتجاهات من أهمها : ( العطار : ص V • ( )

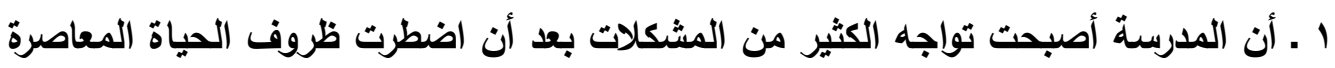

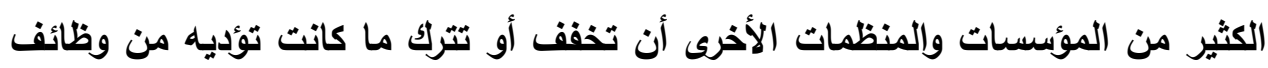

\section{تريوية.}

r ـ أن الكثير من المنظمات الاجتماعية والجماعات المختلفة قد فقدت فى نظر البعض كل قصد تربوي ينطوي عليه نشاطها ، وكأن المدرسة هى المؤسسة الوحيدة التى يتوافر لها ذلك القصد ومن ثم أخذ الكبار من أولياء الأمور والمهتمين بالعملية التريوية

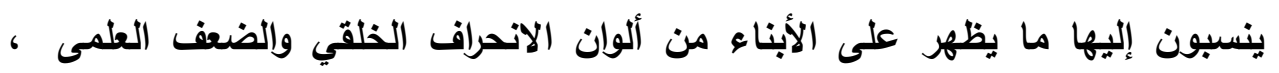

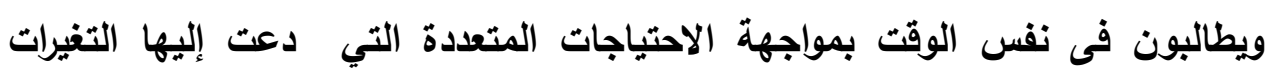
الاجتماعية المعاصرة والتي تتسم بالسريعة المتلاحقة التى تغير فى ظروف معيشتهم وعلاقاتهم وطرق تفاعلهم. r ـ أن المدرسة وهى تواجه كل هذه التحديات والمسائل والمطالب تحاول أن تقوي نفسها لتسد هذا الفراغ الذي وجد بينها ويين المؤسسات الأخرى ومن هنا ظهرت الكثير من

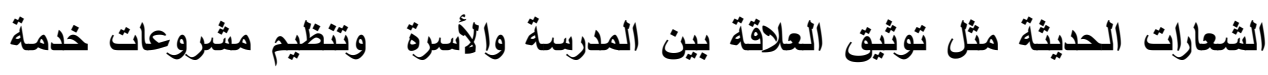

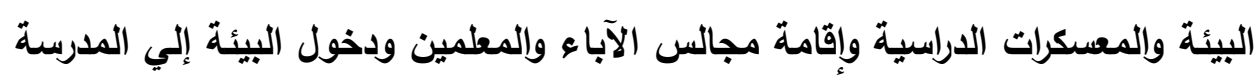

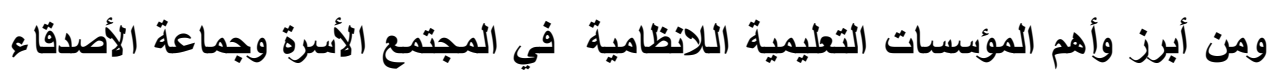

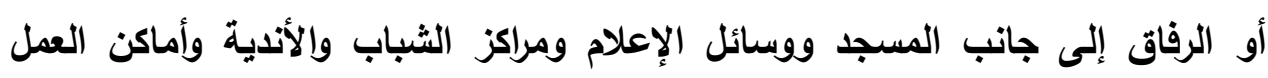

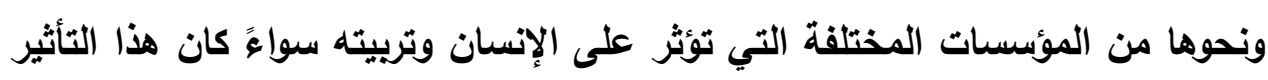

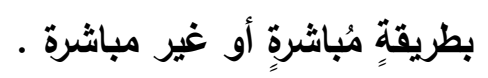
ومعنى هذا أن تربية الإنسان لابد أن تتم إلا من خلال بعض مض فئر المؤسسات الاجتماعية المتعددة

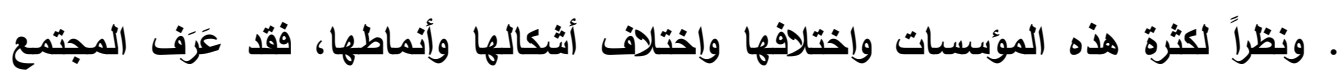


العربي طوال تاريخه الطويل عدداً من هذه المؤسسات الاجتماعية التربوية والتعليمية المختلفة التي كانت نتيجة طبيعية لعديد من المطالب والتحديات والتغيرات التي ظهرت بين حينٍ وآخر على المجتمع. بل إن كل مؤسسة من هذه المؤسسات التريوية التي عُرفت إنما جاءت

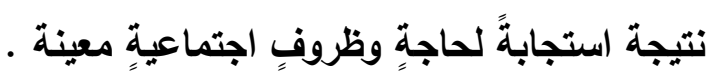
وتتضح دلائل وظواهر العدالة الاجتماعية داخل الأسرة من خلال تعامله التهله الآباء لأبنائهما في

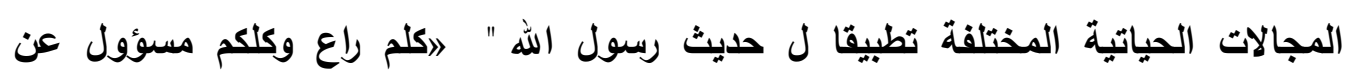
رعيته..، وتؤسس هذه الرعاية على الوعي الكامل، وإدراك الوالدين للعلاقة وللمسؤولية التريوية والنفسية، والالتزام بالأصول القرآنية ونصوص سنة الرسول الثائه الثريفة في الاعوة

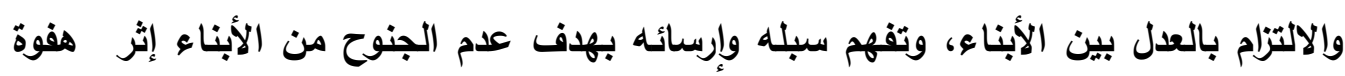
غير مقصودة من تحيز أو تفرقة من الوالدين لأحد الأبناء .وتتضح مظاهر العدالة الاجتماعية

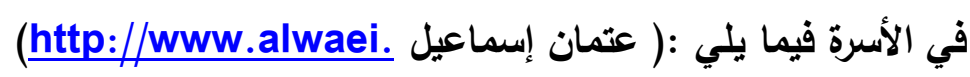
1 ـ العواطف والمشاعر.. وهي من أخطر وأدق أنواع ممارسة العدل داخلم الخل الأسرة من الآباء

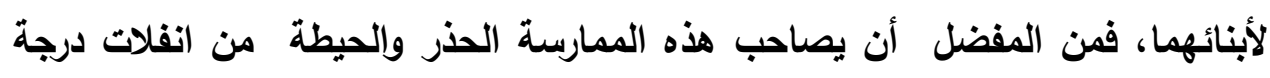

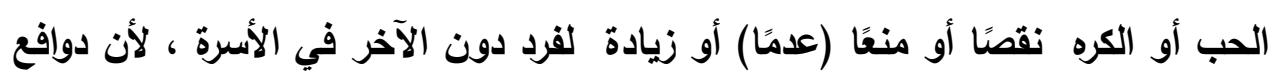

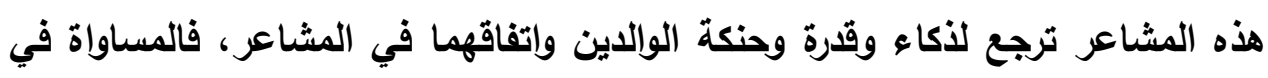

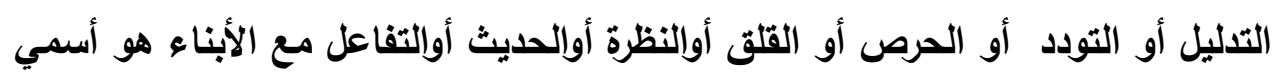

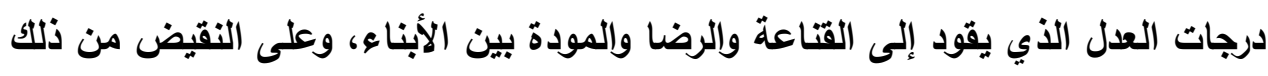
فأي هزة أو سقطة أو تغيير في هذا المحور تكون نتيجته إضمار الحقد بين الأبناء، وشحن النفوس بالكراهية والعداوة والبغضاء.

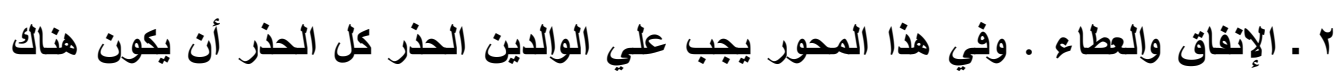

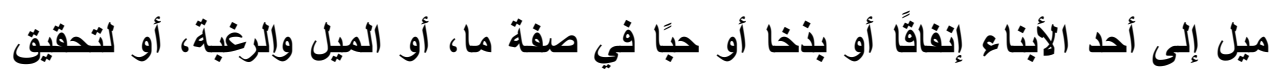
هدف دون الآخر من الأولاد ، على أنه من الطبيعي ومن العدل أن كل الأبناء يأخذون

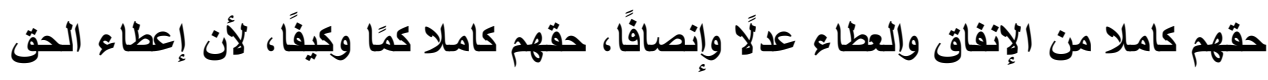
كاملا هو مراعاة لحق الله في الرعاية، كما أنه أمانة من الوالدين في هذه المسؤولية

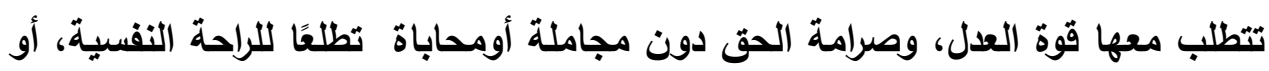

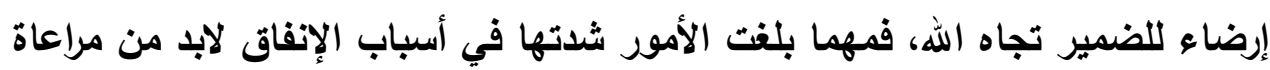


الحذر من عواقب التساهل في المجاملة والمحاباة من ناحية، والمنع والبخل من ناحية أخرى، فالعدل في مساواة الإنفاق نتيجته الحب وقوة الترابط ودوام العلاقة بين الأبناء

وقوتها.

r ـ التعليم.. رغم أن هذا المحور يرجع أساسا لمبدأ الفروق الفردية بين الأولاد ، فلابد من

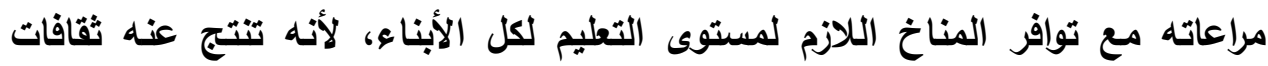
مختلفة ينتج عنها تنافر الآراء وطيش العقول، ولكن مبدأ العدل في تعليم الأبناء يحقق الابل وحدة الفكر ووحدة الثقافة ووحدة الرأي واللهاف كما أنه ينتج روعة الحوار والإبداع

والجدل المفيد ويحقق للأبناء راحة النفس والوجدان وسمو التعامل ولباقة الأسلوب. - الاختلاف حول علاقة المؤسسات التعليمية النظامية والللانظامية (http://elraaed.com

ارتبط بالتغيرات التي أحاطت بوضع المدرسة اجتماعيا بانقسام الرأي بين الآباء والمسؤولين والمربين بصدد هذه الاتجاهات السابقة ونشأ عن هذا الاختلاف آراء ونظريات تربوية:

منها ما استمر علي الاعتقاد التقليدي بأن المدرسة لها جواتب مخصصة و ليس لها أن تزيد علي وظيفتها التعليمية أي وظائف أخرى يمكن أن تقوم بها الأسرة والمنظمات الدينية

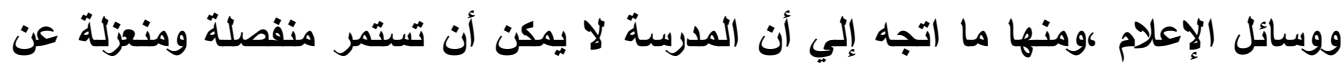

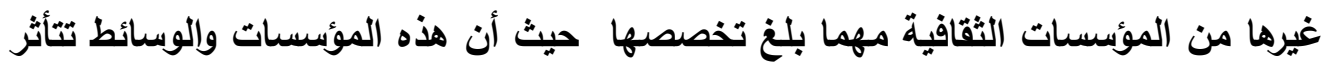
وتؤثثر بفعل التربية ذاتها ممثلا فيما تحدثه من تغيير في سلوك الكبير والصغير علي السواء. ومنها ما أخذ موقفا وسطا بين الرأيين السابقين .،وأخذ أصحاب كل رأي هذه من الآراء بفلسفة موقفهم فكان لكل منهم نظرية عن طبيعة الإنسان الفرد وكيفية تعلمه وعلاقته بمجتمعه وعن معنى الثقافة وعلاقة التربية بها ،وقد تضمن هذا الانقسام اختلافا كبيرا حول تأثير ما يسمى " بالتعليم النظامي والتعليم اللانظامي " وأهمية المؤسسات الثقافية التي يحدث فيها هذا التعليم ، لا يميز الاتجاه الحديث بين هذين النوعين إلا من حيث درجة تأثير كل نوع من التعليم علي نمو الفرد ومدى انتظام واستمرار هذا التأثير ودرجة وضوح الأهداف لهن التي تصحبه والأسس التي يقوم عليها. 
التكامل بين المؤسسات التعليمية النظامية واللانظامية في تحقيق العدالة الاجتماعية

$$
\text { لطلاب الثانوية العامة : لبن }
$$

يري الباحث أنه بموجب هذا الاتجاه تعتبر الخبرات التي تقدمها المدرسة تعبيرا عن خبرات أوسع وأشمل هي تلك الخبرات الناتجة عن المجتمع والذي أنشأ المدرسة وعملية التشكيل

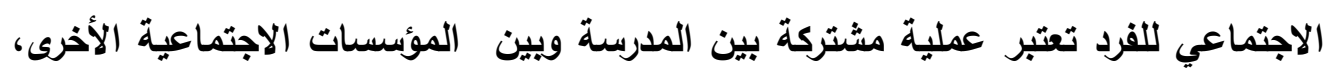
وتأثير المدرسة علي الفرد بين مؤثرات متعددة و كثيرة تحدث في إطار الوعي أو اللاوعي و

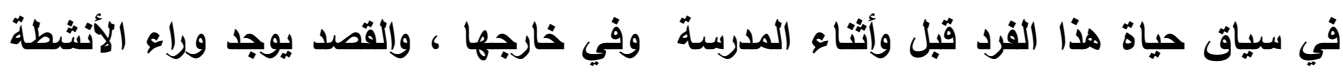

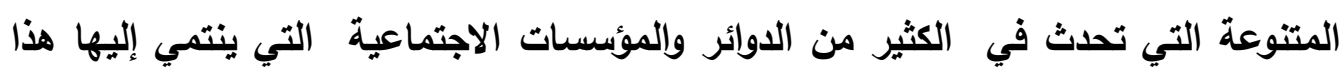
الفرد فهو يتواجد مثلا خلال العلاقات الأسرية حينما يصر الآباء علي تعليم أولادهم عادات وقيما محددة وعندما يخضع الأبناء لقوانين معينة باعتبارهم مشتركون في إحدى الأندية

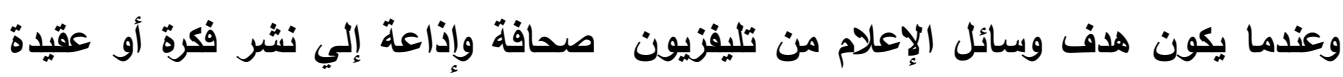

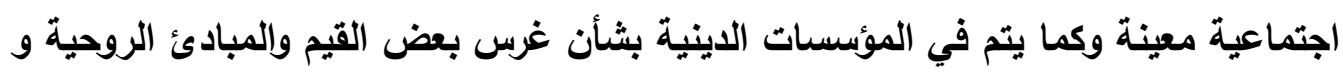

الخلقية.

ومن هنا فالتعليم لا ينقسم إلي نظامي ولانظامي كما لا يجب أن نخصص المدرسة "

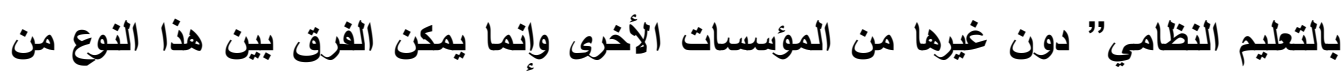

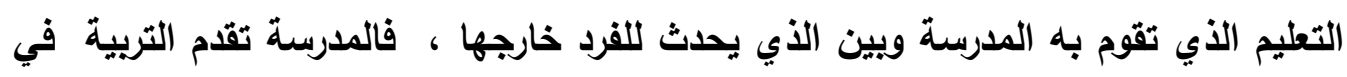
ضوء فلسفة المجتمع وعلي أساس من الوضوح الفكري فترسم الأهداف وتتخذ من الوسائل المتعددة الفنية والعلمية ما بجعلها قادرة علي تحقيق هذه الأهداف تحقيقا متكاملا في فترة

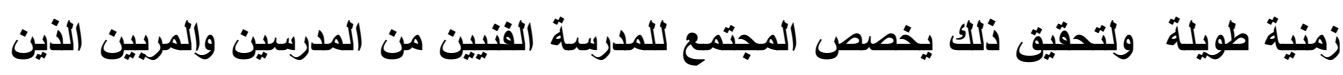

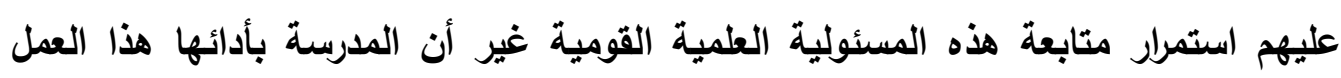

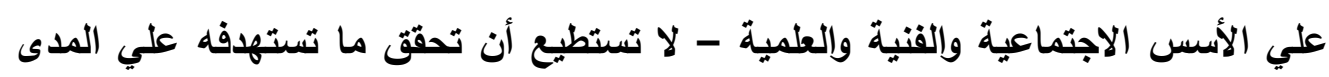
البعيد إلا إذا توافر الوعي من جانب المؤسسات الأخرى بواجباتها نحو تعزيز عمل المدرسة الأنه

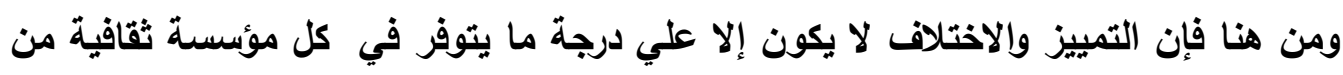

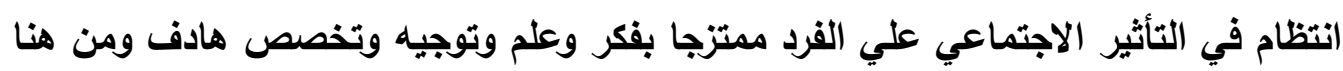

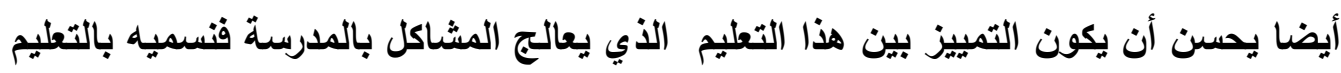

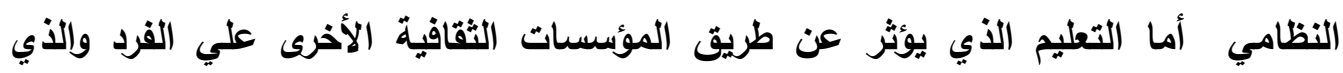


نسميه بالتعليم اللانظامي تصبح المشكلة ، هي كيفية اتساق هذين النوعين من التعليم وأن

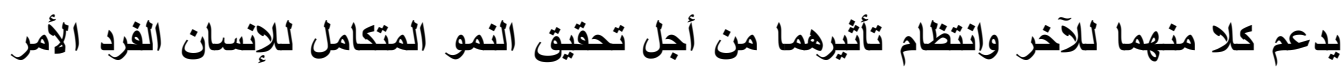

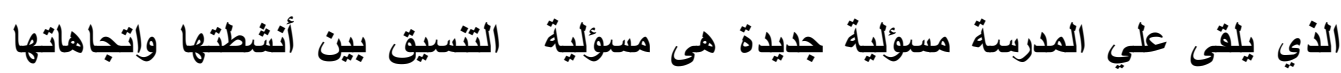

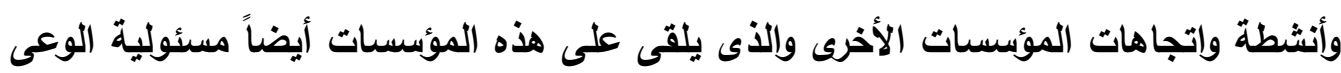

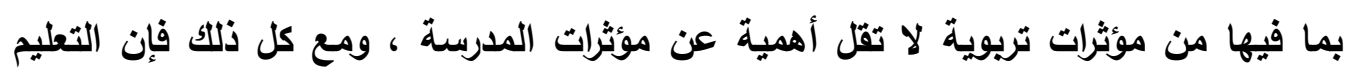

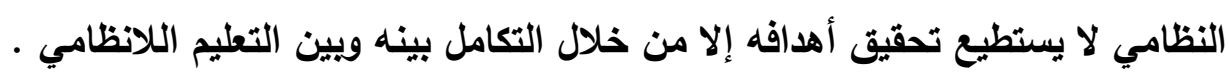
ويري الباحث أن : المؤسسات التعليمية تؤثر بنوعيها النظامي والنلا النظامي، على النى تشكيل وصقل شخصية الأفراد، وتكوين الاتجاهات والقيم والمعارف لايهم.

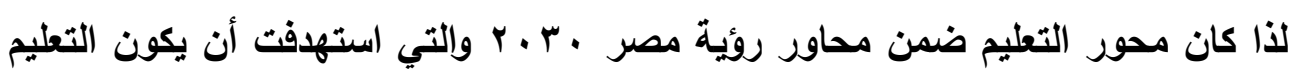

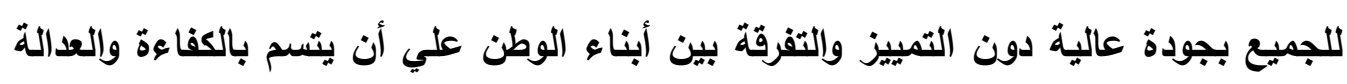
والمرونة والاستمرارية ، وأن يساهم في بناء الثخصية المتكاملة واطلاق امكاناتها إلي أقصي

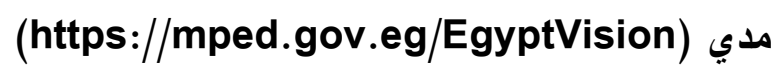
المحور الرابع : نتائج الدراسة و التوصيات: يتناول هذا المحور الجانبين الآتيين: أولا النتائج: توصلت الاراسة الى مجموعة من النتائج :

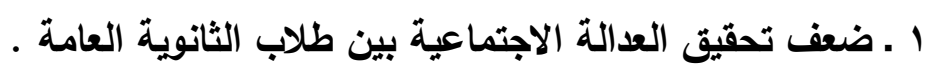

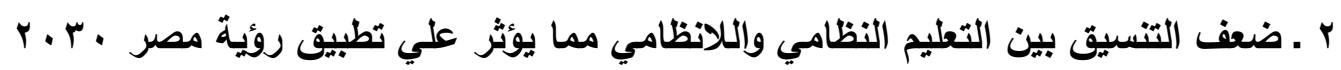

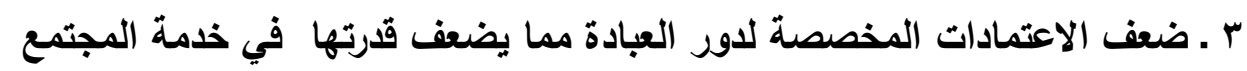
؛ضعف تأهيل الوالدين والإعلام ورجال الدين مما يقلل من توصيل رسالة روئة مصر .$r \cdot r$. 
توصلت الدراسة إلى مجموعة من التوصيات :

1 ـ ضرورة أن تتوافق برامج التأهيل للأسرة والإعلام والأئمة في دور العبادة معات معروئية مصر

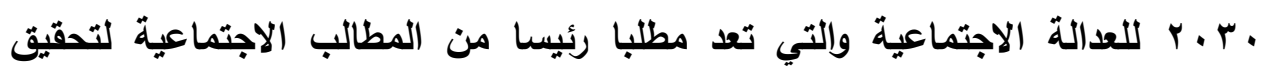

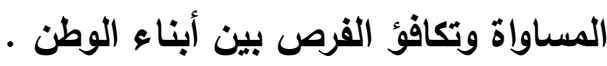

r ـ ضرورة وجود برامج تدريبة للوالدين والاعلاميين و رجال الدين في كيفية التواصل مع الوع الثباب و تقايم الدعم لهم.

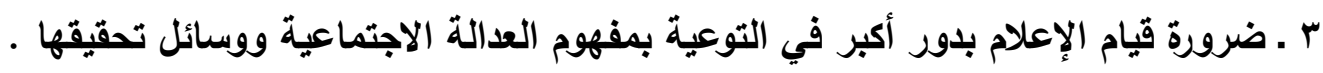

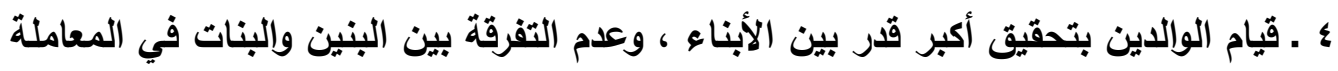




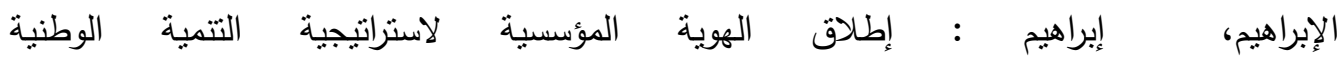

\section{https://www.raya.com/home/print/}

http://www.alwaei.gov.kw إسماعيل ، عثمان: العدل الأسري بواعثه وثماره

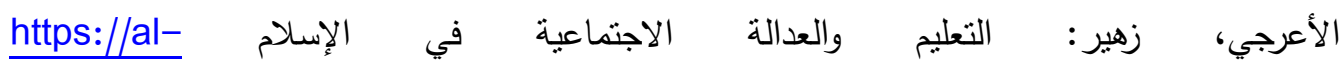

7awza.org/show.php?cat=8\&id=149

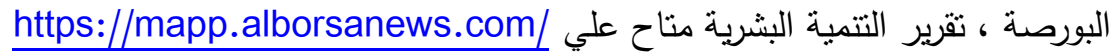

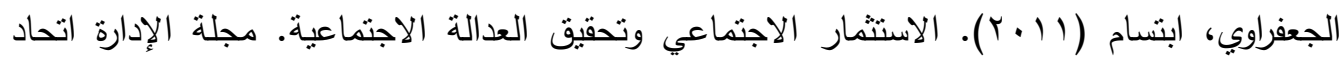

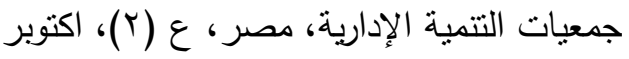

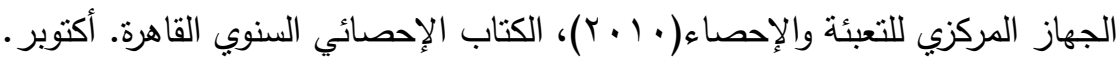

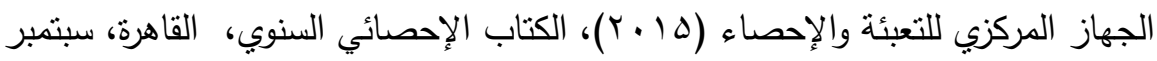

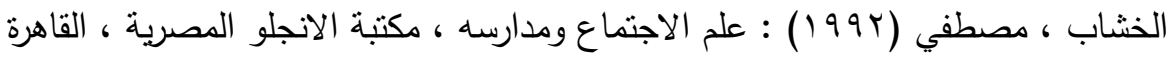

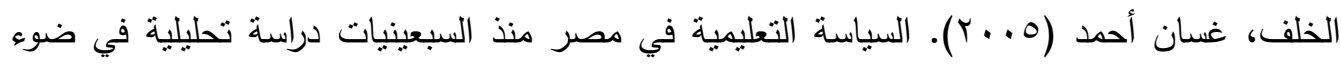
مفهوم العدالة الاجتماعية، رسالة ماجستير، غير منشورة، معهذ الدراسات والبحوث التربوية،

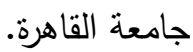

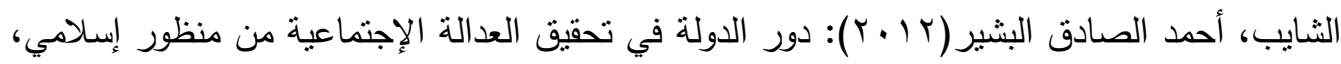

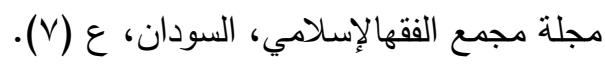
الثريف، محمد بن شاكر : نحو تربية إسلامية راثدة من الطفولة حتي البلوغ ، مكتبة الملك فهر الوطنية

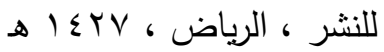

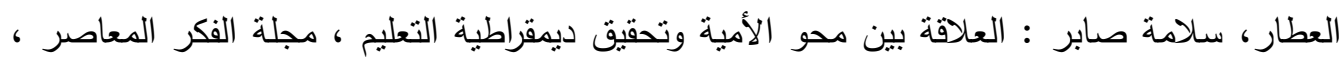

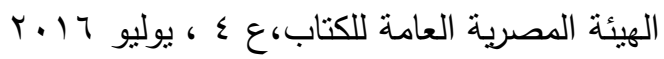

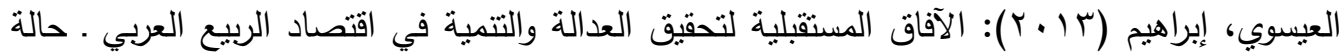
مصر، مجلة النتمية والسياسات الاقتصادية، تصدر عن المعهد العربي للتخطيط والتتمية

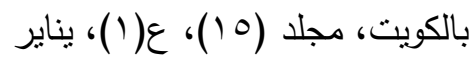

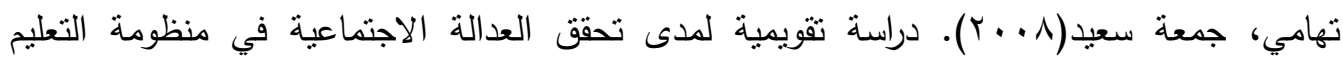
الأساسي في ضوء بعض المتغيرات المجتمعية المعاصرة، رسالة دكتوراه غير منشورة، كلية

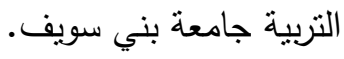
جرار، أماني غازي: التربية الإنسانية والاخلاقية ، دار اليازوري العلمية للنشر والتوزيع 


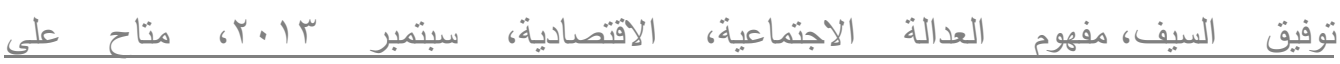

\section{: http://www.aleqt.com26/3/2019.الرابط.}

دياب، شحاته أبوزيد شحاته(.99 1). مبدأ المساواة فى الدساتير العربية، رساله دكتوراه غير منشوره،

كليه الحقوق، جامعة عين شمس.

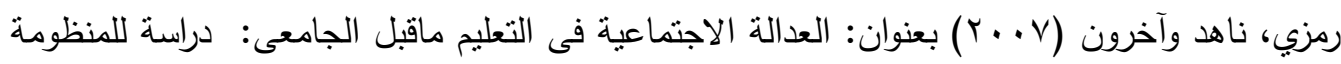

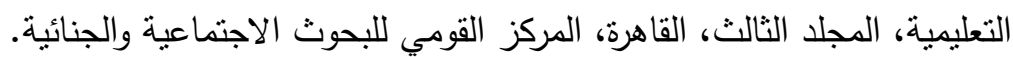

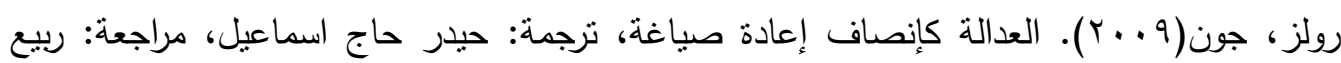

$$
\text { شلهوب، بيروت، مركز دراسات الوحدة العربية. }
$$

سعادة، رضا(7 (191): الإسلام والعدالة الاجتماعية، مجلة الفكر العربي، معهز الإنماء العربي، لبنان،

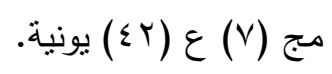

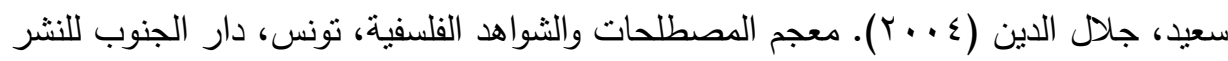

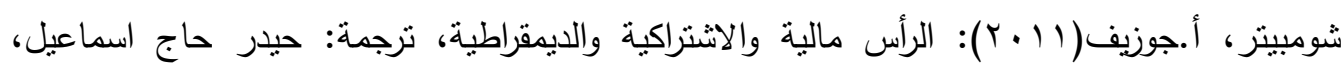
بيروت، مركز دراسات الوحدة العربية.

عبد الحمبد جابر ، كاظم أحمد خيري (•191 (م) : مناهج البحث فى التربية وعلم النفس ، طب ، القاهرة ، دار النهضة العربية

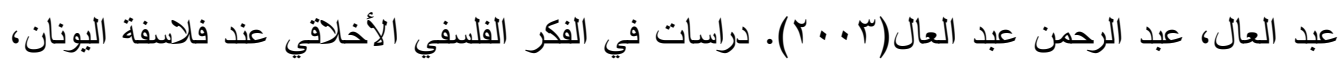

$$
\text { دار الوفاء، الإسكندرية. }
$$

عبد الدائم، عبد اله (ـ191)). التربية عبر التاريخ من العصور القديمة حتى أوائل القرن العشرين،

$$
\text { بيروت، دار العلم للملايين }
$$

عوض ، توفيق عوض (199 (1):علاقة مجانية تعليم المرحلة الأولي في مصر بالعدالة الاجتماعية بين

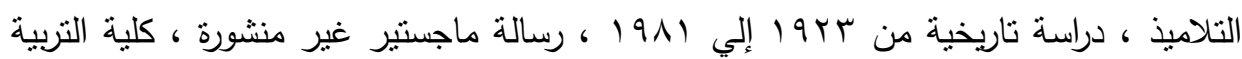

$$
\text { عين شمس }
$$

فورهولت، أدفو وماير، توماس (• ( ب). المجتمع المدني والعدالة، ترجمة: النشار، راندا وآخرون،

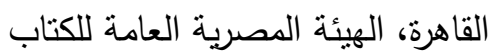

كبة ،سلام : العدالة الاجتماعية ، المفهوم والكوابح والمعالجات ، العراق نموذجاب http://iraqicparchives.com

ـ مطر ، أميرة حلمي( 99 ( ).جمهورية أفلاطون، مهرجان القراءة للجميع ؟ 9 ـ مكتبة الأسرة.القاهرة. سليمان ، مكي ادم : أساسيات في التربية وعلم النفس وطرق التدريس ، دار الفكر العربي ، القاهرة 
دور المؤسسات التعليمية اللانظامية............

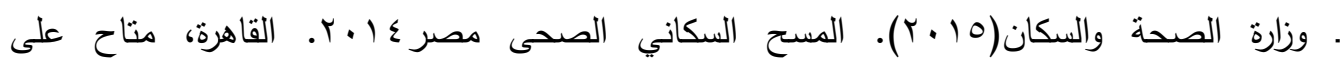
موقع:https://dhsprogram.com

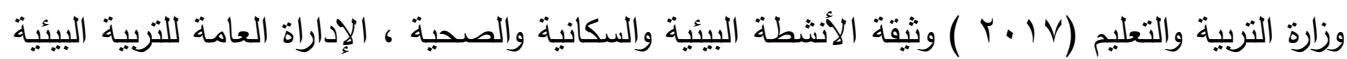
والسكانية والصحية ، قطاع التعليم العام ، القاهرة . ( https://mped.gov.eg/EgyptVision) وزارة التخطيط والتتمية الاقتصادية

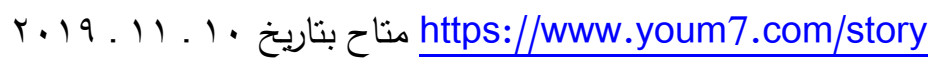
| 19 متاح بتاريخ س 11 https://www.sis.gov.eg/Story

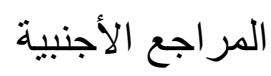

Robertson, Susan L. and Dale, Roger (2013). The social justice implications of privatisation in education governance frameworks: a relational account, Oxford Review of Education, Vol. (39), No. (4), U.S.A. 